\title{
Large-eddy simulation of the tidal-cycle variations of an estuarine boundary layer
}

\author{
Ming Li, ${ }^{1}$ Senthilkumaran Radhakrishnan, ${ }^{2}$ Ugo Piomelli, ${ }^{3}$ and W. Rockwell Geyer ${ }^{4}$ \\ Received 7 August 2009; revised 8 December 2009; accepted 4 March 2010; published 3 August 2010.
}

[1] The estuarine boundary layer affected by a horizontal density gradient exhibits temporal evolution over a tidal cycle, in a manner similar to the diurnal cycle of the ocean surface mixed layer. A large eddy simulation (LES) model is developed to investigate the physics controlling the growth of the boundary layer during the flood tide and restratification during the ebb tide. Turbulent kinetic energy, momentum and salt fluxes, bottom stress, and energy dissipation rates calculated from the LES model all show a strong flood-ebb asymmetry. Analysis of the turbulent kinetic energy (TKE) budget shows a primary balance between shear production and dissipation in the well-mixed boundary layer over the tidal cycle. However, TKE transport term is found to be important across the edge of the boundary layer during the flood tide so turbulent energy generated in the bottom boundary layer can be transferred to the stratified pycnocline region. Tidal straining leads to a small and weakly convective region inside the boundary layer during the flood tide but the strain-induced buoyancy flux does not make a significant contribution to the turbulence generation. Additional LES runs are conducted by switching off the baroclinic pressure gradient term in the momentum equation and the tidal straining term in the salinity equation to show that the baroclinic pressure gradient is the main mechanism responsible for generating the flood-ebb mixing asymmetry.

Citation: Li, M., S. Radhakrishnan, U. Piomelli, and W. Rockwell Geyer (2010), Large-eddy simulation of the tidal-cycle variations of an estuarine boundary layer, J. Geophys. Res., 115, C08003, doi:10.1029/2009JC005702.

\section{Introduction}

[2] Much work has been devoted toward understanding the temporal evolution of the surface mixed layer in the open ocean. Over a diurnal cycle, daytime heating leads to restratification in the mixed layer while nighttime convection causes entrainment and deepening of the mixed layer. In estuaries and shelf seas affected by a horizontal density gradient, the bottom boundary layer exhibits temporal evolution over a tidal cycle similar to the diurnal cycle of the surface mixed layer: the boundary layer entrains and grows during the flood phase but may restratify during the ebb phase. Understanding the physical mechanisms controlling the growth and restratification of the estuarine boundary layer is the topic of this paper.

[3] Recent observations have provided unprecedented detail on the temporal and spatial variability of turbulent mixing in estuaries and shelf seas. In particular, significant

\footnotetext{
${ }^{1}$ Horn Point Lab, University of Maryland Center for Environmental Science, Cambridge, Maryland, USA.

${ }^{2}$ Department of Mechanical Engineering, University of Maryland, College Park, Maryland, USA.

${ }^{3}$ Department of Mechanical and Materials Engineering, Queen's University, Kingston, Ontario, Canada.

${ }^{4}$ Department of Applied Ocean Physics and Engineering, Woods Hole Oceanographic Institution, Woods Hole, Massachusetts, USA.

Copyright 2010 by the American Geophysical Union. 0148-0227/10/2009JC005702
}

asymmetry in turbulent mixing was found over a floodebb tidal cycle. Jay and Smith [1990a, 1990b] analyzed data collected from the Columbia River estuary and found enhanced shear and stratification during ebb tides but stronger mixing and weaker stratification during flood tides. In the weakly stratified flows found in regions of the continental shelf influenced by lateral fresh water inputs, Simpson et al. [1990] independently discovered the same phenomenon and described the switching between the stratified and mixed states over a single tidal cycle as strain-induced periodic stratification (SIPS). Geyer et al. [2000] estimated the eddy viscosity in the Hudson River and found that flood values exceeded ebb values by a factor of 2 . Based on dissipation measurements in the Liverpool Bay region of freshwater influence, Rippeth et al. [2001] hypothesized that tidal straining produces instabilities in the water column that release additional energy for convective mixing toward the end of the flood tide. Subsequently, Stacey and Ralston [2005] proposed that the mixing asymmetry in the flow is due to the strain-induced buoyancy flux, which is stabilizing on ebb tides but destabilizing on flood tides. However, in a recent dye study, Chant et al. [2007] found that the growth of the tidally driven bottom boundary layer in the Hudson River is primarily driven by the bed stress while tidal straining only plays a minor role in the entrainment process.

[4] Despite these recent advances in observations of estuarine mixing processes, several key questions on the flood-ebb tidal asymmetry remain unanswered. What are the 
relative roles of baroclinic pressure gradient and tidal straining in estuarine dynamics? Is the flood-ebb mixing asymmetry caused by the flood-ebb asymmetry in the bed stress or by the tidal straining of the density field? How does the strain-induced buoyancy production compare with shear production and turbulent transport in the turbulence kinetic energy budget?

[5] The large eddy simulation (LES) model has potential to shed new light on the physics of estuarine mixing processes and provide answers to those questions. LES is a numerical technique that directly resolves the large, flux-carrying turbulent eddies, while modeling the small, more isotropic, subgrid-scale (SGS) eddies. Most of the success of LES in geophysics has been in neutral or unstably stratified environments [e.g., Wyngaard, 1992, Mason, 1994], but the stratified turbulence problem has been more of a challenge, due to the small spatial scales of the turbulent eddies and the extreme anisotropy of the outer scales of flow. Notwithstanding these challenges, there has been progress in modeling stratified flows with LES. Mason and Derbyshire [1990] and Brown et al. [1994] applied LES to stably stratified atmospheric boundary layers, while Sullivan et al. [1998] and Otte and Wyngaard [2001] used LES to investigate entrainment processes in the interfacial layer capping the atmospheric boundary layer.

[6] In oceanography, LES has been used to study turbulent mixing processes in the ocean-surface mixed layer [e.g., McWilliams et al., 1997; Skyllingstad et al., 1999; Li et al., 2005]. Skyllingstad and Wijesekera [2003] extended the upper ocean LES model by using a shaved-cell approach to simulate flows over two-dimensional obstacles, whereas Denaro et al. [2007] developed a large-eddy simulation method based on the finite volume approach and evaluated it for buoyancy-driven turbulence in the absence of rotational effects. Taylor and Sarkar [2007, 2008a, 2008b] performed large eddy and direct simulations of a stratified bottom Ekman layer, including the role of internal waves and proposed modifications to the standard logarithmic law in the near-wall.

[7] In a pilot study, Li et al. [2008] adapted an upper-ocean LES model to investigate asymmetric tidal mixing affected by the horizontal density gradient. They conducted several model runs to simulate periodic restratification in weakly stratified shelf regions and found that the depth-integrated buoyancy production is less than $5 \%$ of the integrated shear production in all the runs in which the tidally averaged horizontal Richardson number falls into a range $0.1<\overline{R i_{x}}<0.8$. They further demonstrated that $\overline{R i_{x}}=H /(-L)$, where $H$ is the water depth and $L$ is the Monin-Obukhov length. According to previous mixed-layer studies by Li et al. [2005], the transition from the shear to convective turbulence occurs at $\overline{R i_{x}}=$ $H /(-L) \approx 4.5$. For typical values of tidal currents and the horizontal density gradient found in the weakly stratified shelf regions, $\overline{R i_{x}}$ is generally less than about 1 . Therefore, it seems unlikely that the flows will switch from shear- to buoyancy-driven turbulence over the ebb-flood tidal cycle. $L i$ et al. [2008] also conducted a run with permanent stratification. Since the LES model required a uniform grid size in all three directions, it had difficulty in resolving the stratified pycnocline, resulting in a subsurface jet that is more pointed than the observed during the flood tide. Consequently, it remains unclear how the baroclinic pressure gradient and tidal straining contribute to turbulence mixing in stratified water representative of a typical partially mixed/stratified estuary.

[8] In this work, we simulate the growth and restratification of an estuarine boundary layer in stratified water. To conduct such simulations, we have extended a finite-volume engineering LES model to oceanic applications. The model allows variable grid sizes so higher resolution can be placed in the stratified pycnocline. The governing differential equations (conservation of mass and momentum and the scalar transport) are discretized on a non-staggered grid using a curvilinear finite-volume code. The LES model has been validated by Silva Lopes and Palma [2002] in isotropic turbulence, by Silva Lopes et al. [2006] in an S-shaped duct, and by Radhakrishnan et al. [2006] for nonequilibrium flows. In particular, Radhakrishnan and Piomelli [2008] have validated the model against the laboratory experiments of Jensen et al. [1989] for oscillating boundary layers. In their numerical experiments, Radhakrishnan and Piomelli [2008] explored a number of subgrid scale and wall-layer models. With a finite-volume grid design, this LES model has the capability to resolve estuarine and coastal flows affected by varying bathymetry and shoreline geometry.

[9] The studies in the Hudson River suggest that mixing in the interior is controlled by entrainment between the boundary layer and the pycnocline above [Chant et al., 2007], but processes in this transition zone have not been adequately characterized. By analyzing the turbulent kinetic energy budget, we shall examine if turbulent transport term plays an important role in supplying turbulent kinetic energy from the bottom boundary layer to the entrainment zone, as suggested by Simpson et al. [1996] and Stacey et al. [1999]. We will also examine the hypothesis of Stacey and Ralston [2005] that the turbulence structure is inherently altered by the straining mechanism. If convective processes significantly contribute to the turbulence in this region, the overall efficiency of conversion from kinetic to potential energy may be significantly affected, with implications for the overall estuarine dynamics as well as the dynamics of the stratified turbulence.

[10] The plan for the paper is as follows: in section 2 we describe the finite-volume LES model. Section 3 is devoted to an analysis of turbulent statistics over a tidal cycle. In section 4 we analyze the turbulent kinetic energy budget and investigate the roles of baroclinic pressure term and tidal straining term in the generation of tidal-mixing asymmetry. Concluding remarks are made in section 5 .

\section{Model Description}

[11] In large-eddy simulations, the velocity and scalar/ density fields are separated into a resolved (large scale) and a subgrid (small-scale) field, by a spatial filtering operation [Leonard, 1974]. The conservation equations of mass, momentum, temperature, and salinity for an estuarine LES model are given by

$$
\begin{gathered}
\frac{\partial u_{i}}{\partial x_{i}}=0 \\
\frac{\partial u_{i}}{\partial t}+\frac{\partial}{\partial x_{j}}\left(u_{i} u_{j}\right)=\delta_{i 1} \frac{1}{\rho}\left(F_{\text {tide }}-\frac{\partial \bar{P}_{b}}{\partial x_{1}}\right)-\frac{1}{\rho} \frac{\partial p}{\partial x_{i}}+\frac{\partial \tau_{i j}}{\partial x_{j}}+v \nabla^{2} u_{i} \\
-\delta_{i 3} g \frac{\rho^{\prime}}{\rho}
\end{gathered}
$$




$$
\begin{gathered}
\frac{\partial T}{\partial t}+\frac{\partial}{\partial x_{j}}\left(T u_{j}\right)=\frac{\partial q_{j}}{\partial x_{j}}+\gamma \nabla^{2} T \\
\frac{\partial S}{\partial t}+\frac{\partial}{\partial x_{j}}\left(S u_{j}\right)=-u_{1} \frac{\partial \bar{S}}{\partial x_{1}}+\frac{\partial \theta_{j}}{\partial x_{j}}+\kappa \nabla^{2} S
\end{gathered}
$$

in which $x_{i=1,2,3}(x, y, z)$ are the streamwise, spanwise, and vertical directions; the resolved velocity components in these directions are $u_{1}, u_{2}$, and $u_{3}$ (or $u, v$, and $\left.w\right) ; \tau_{i j}, \mathrm{q}_{j}$, and $\theta_{j}$ are the modeled subgrid-scale terms that arise in the momentum, temperature $(T)$, and salinity $(S)$ equations, respectively, with $p$ the pressure, $\rho^{\prime}$ the density perturbation, $g$ the gravitational constant, $v$ the molecular viscosity, and $\gamma$ and $\kappa$ the diffusivities of heat and salt. The model assumes a rigid-lid surface and the tidal flow is driven by an oscillating pressure gradient $\frac{1}{\rho} F_{\text {tide }}=-\frac{1}{\rho} \frac{\partial p_{\text {tide }}}{\partial x}$. Since the LES domain is too small to resolve the entire estuary, the effects of estuarine circulation are included through forcing terms. In the streamwise component of the momentum equation, we add a large-scale pressure gradient given by

$$
-\frac{1}{\rho} \frac{\partial \bar{P}_{b}}{\partial x}=-g \frac{\partial \eta}{\partial x}-\frac{g}{\rho_{0}} \int_{z}^{\eta} \frac{\partial \rho^{\prime}}{\partial x} d z^{\prime}
$$

in which $\eta$ is the surface elevation. The first term on the righthand side of (5) represents fresh water pileup at the river head while the second term represents baroclinic pressure gradient due to sloping isopycnals. In the salinity equation, a largescale advection term $u \frac{\partial \bar{S}}{\partial x}$ includes the effect of tidal straining. This set of governing equations can be derived mathematically from the filtered LES equations by employing a multiscale expansion in which the inner scale is the resolved velocity from the LES, and the outer one is determined by the large-scale estuarine circulation, or obtained from a consideration of estuarine momentum and salt balance [ $\mathrm{Li}$ et al., 2008].

[12] The SGS stresses and scalar fluxes are modeled using an eddy-viscosity approximation

$$
\begin{gathered}
\tau_{i j}^{a}=\tau_{i j}-\frac{\delta_{i j}}{3} \tau_{k k}=-2 \nu_{t} \chi_{i j}, \\
q_{i}=-\frac{v_{t}}{P r_{t}} \frac{\partial T}{\partial x_{i}}, \\
\theta_{i}=-\frac{\nu_{t}}{P r_{t}} \frac{\partial S}{\partial x_{i}},
\end{gathered}
$$

where $\chi_{i j}$ is the resolved strain-rate tensor

$$
\chi_{i j}=\frac{1}{2}\left(\frac{\partial u_{i}}{\partial x_{j}}+\frac{\partial u_{j}}{\partial x_{i}}\right)
$$

and the turbulent Prandtl number $P r_{t}$ is assumed to be 1 . We use the Smagorinsky eddy-viscosity model [Smagorinsky, 1963] given by

$$
\nu_{t}=\left(C_{s} \Delta\right)^{2}\left(2 \chi_{i j} \chi_{i j}\right)
$$

in which $\Delta=\left(\Delta_{x} \Delta_{y} \Delta_{z}\right)^{1 / 3}$ is the filter width and $C_{s}=0.1$ is chosen. This SGS model was chosen primarily for cost reasons: we tested the dynamic Lagrangian-averaged model [Meneveau et al., 1996], which is generally more accurate than the Smagorinsky model (especially in the near-wall region), but found no improvement in the prediction of the Reynolds stresses and only marginal differences in the mean velocity and salinity profiles. The Lagrangian dynamic model, however, required doubling the CPU time of the Smagorinsky model. This increased cost is due to additional filtering operations, which require significant communication between processors. Given the already extreme computational cost of this calculation (see below), it was decided to use the simpler model to be able to integrate the equations for a longer time.

[13] The governing differential equations (1) to (4) are discretized on a nonstaggered grid using a curvilinear finite volume code (the calculations presented here, however, used a Cartesian orthogonal geometry). The method of Rhie and Chow [1983] is used to avoid pressure oscillations. Both advective and diffusive fluxes for the momentum and scalar equations are approximated by second-order central differences. The model can use the Crank-Nicolson scheme to advance the wall-normal diffusive terms in time, and the Adams-Bashforth scheme for all the other terms, or can be fully explicit if the Adams-Bashforth scheme is used for all terms. In flows, such as the one under study, that are homogeneous in the $y$ direction, Fourier transforms can be used to reduce the three-dimensional Poisson equation into a series of two-dimensional Helmholtz equations in wave number space, which are then solved iteratively using the biconjugate gradient stabilized method. The code is parallelized using the MPI message-passing library and the domain-decomposition technique. As mentioned above, this model has been extensively tested [Silva Lopes and Palma, 2002; Silva Lopes et al., 2006; Radhakrishnan et al., 2006; Radhakrishnan and Piomelli, 2008]. To examine how well the new finitevolume LES model works in stratified fluids, we used it to simulate stably stratified open channel flow driven by a uniform pressure gradient and a surface heat/density flux. The results were then compared with those obtained from a finitedifference LES model by Taylor et al. [2005]. The two LES models show very good agreements on the low-order turbulence statistics. Detailed comparison results can be found in the appendix.

[14] To investigate the estuarine mixing problem, we use a model domain of 30 (streamwise) $\times 20$ (spanwise $) \times$ 10 (vertical) $(\mathrm{m})$ and a grid size of $120 \times 80 \times 120$. Since density stratification is dominated by salinity difference in estuaries, uniform temperature is assumed and constant in time. Periodic boundary conditions are used in the streamwise $(x)$ and spanwise $(y)$ directions. At the free surface, the wallnormal velocity is set to zero, as are the vertical derivatives of the streamwise and spanwise velocity components across the sea surface. A zero-flux boundary condition is imposed for 

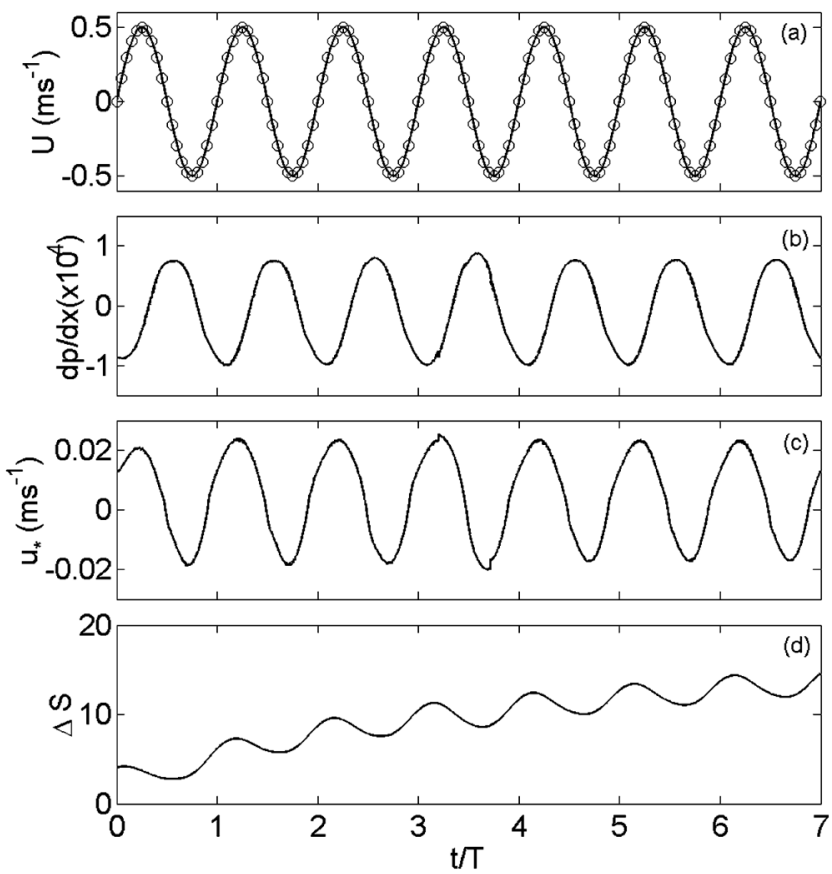

Figure 1. Time series of (a) imposed (open circles) and model-produced (solid line) depth-averaged current, (b) oscillating tidal pressure gradient, (c) bottom friction velocity, and (d) top-to-bottom salinity difference over seven tidal cycles.

salinity at the top and bottom boundaries. To prescribe the bottom boundary condition for the momentum equation, we use the wall-layer model by applying the logarithmic law at the first grid point. Given the average velocity $U_{o l}$ in the outer layer (at the first grid point $z_{o l}$ ), one can relate it to the bottom friction velocity $u *$ by solving

$$
\frac{U_{o l}}{u_{*}}=\frac{1}{\kappa} \log \frac{z_{o l}}{\delta},
$$

where $\kappa=0.41$ is the von Karman constant and $\delta$ is the bottom roughness length. In the model simulations we choose a typical value of $\delta=1 \mathrm{~mm}$ (see Radhakrishnan and Piomelli [2008]for implementation details).

[15] The grid spacings in the two horizontal directions $\Delta x$ and $\Delta y$ are fixed at $0.25 \mathrm{~m}$. In order to resolve better the stratified region in the upper part of the water column, we use nonuniform grid spacing in the vertical direction: $\Delta z$ is equal to $0.2 \mathrm{~m}$ in the bottom $4 \mathrm{~m}$ and decreases linearly to $0.009 \mathrm{~m}$ near the top surface. The calculations were run in fully explicit mode with a constant CFL number of 0.1 , which corresponds to a time step in the range 0.02 to $0.05 \mathrm{~s}$. The tidal pressure gradient $\frac{1}{\rho} F_{\text {tide }}=-\frac{1}{\rho} \frac{\partial p_{\text {tide }}}{\partial x}$ in equation (1) is prescribed to drive an oscillating tidal current $U_{o}=V_{\max } \sin (\omega t)$ with the maximum tidal velocity of $V_{\max }=0.5 \mathrm{~ms}^{-1}$ and a frequency $\omega=1.41 \times 10^{-4} \mathrm{~s}^{-1}$. Since the bottom stress exhibits a flood-ebb asymmetry (to be shown in Figure 4) and affects the depth-integrated momentum balance, prescribing $-\frac{1}{\rho} \frac{\partial P_{\text {tide }}}{\partial x}=\frac{\partial U_{0}}{\partial t}$ leads to a tidal asymmetry in the mean flow and a nonzero net volume flow-rate over a tidal cycle [see
Li et al., 2008]. In a real estuary, the surface slope adjusts within a tidal cycle such that the depth-integrated volume flux follows the expected sinusoidal variation in time. To circumvent this problem we followed the approach normally taken in calculations of steady channel flows, in which the pressure gradient is adjusted at each time step to maintain a constant flow rate through the channel (this technique was used, for instance, in Piomelli [1993]). Here, since we wish the depth-averaged behavior to have a sinusoidal behavior, we modify the standard procedure by assigning the pressure gradient using

$$
\frac{1}{\rho} F_{\text {tide }}=\left(\frac{\partial p_{\text {tide }}}{\partial x}\right)^{n+1}=\left(\frac{\partial p_{\text {tide }}}{\partial x}\right)^{n}+2 \frac{U_{d a}^{n}-U_{o}^{n}}{\Delta t}-\frac{U_{d a}^{n-1}-U_{o}^{n-1}}{\Delta t},
$$

where superscript $n$ denotes the time step, and $U_{d a}^{n}$ is the depth-averaged velocity obtained at time step $n$ from the calculation.

[16] To verify the effectiveness of this procedure, we show in Figure 1a the depth-averaged velocity and the desired tidal current, while Figure $1 \mathrm{~b}$ shows the pressure gradient imposed [calculated using equation (12)]. A very good match between the desired current and the actual depth-averaged velocity can be observed. Also notice that the pressure gradient is not symmetric about zero, due to the flood-ebb asymmetry discussed earlier.

[17] Since the depth-averaged velocity is a sinusoidal function, the total salt content in the computational box is conserved over a tidal cycle if $\partial S / \partial x$ does not change with time, as can be seen from equation (4). To prescribe the largescale pressure gradient due to sloping isopycnals and surface, we make the hydrostatic approximation for the large-scale flows and assume an idealized partially mixed estuary with a bilinear salinity distribution given by

$$
S(x, z)=\left(\frac{\partial \bar{S}}{\partial x}\right)(\bar{x}-L)-\frac{N^{2}}{g \beta} z,
$$

where $\partial \bar{S} / \partial x$ is the large-scale horizontal salinity gradient, $\bar{x}$ the distance from the estuary's mouth, $L$ the length of the estuary, and $N$ the buoyancy frequency measuring the strength of the initial vertical stratification and $\beta$ relates salinity to density as $\rho=\rho_{o}(1+\alpha T+\beta S)$. Assuming a level of no motion at the middepth of the estuarine channel, $z=-H / 2$ or the depth-integrated transport associated with the pressure gradient (13) to be zero, we can calculate the sea-level slope needed to balance the baroclinic pressure gradient, that is,

$$
\eta(x)=-\left(\frac{\partial \bar{S}}{\partial x}\right) \frac{\beta H}{2} x
$$

Substituting (13) and (14) into (5), we obtain for the longitudinal pressure gradient,

$$
-\frac{1}{\rho} \frac{\partial \bar{P}_{b}}{\partial x}=\left(\frac{\partial \bar{S}}{\partial x}\right) g \beta\left(z+\frac{H}{2}\right) .
$$


[18] The model was initialized from a state of rest in linearly stratified water. Using values in the Hudson River estuary as an example [cf. Geyer et al., 2000], we took

$$
\begin{gathered}
N^{2}=-\beta g \frac{d S}{d z}=7.7 \times 10^{-4} \times 9.8 \times \frac{10}{10}=7 \times 10^{-3} \mathrm{~s}^{-2}, \\
\frac{\partial \bar{S}}{\partial x}=-4 \times 10^{-4} \mathrm{psu} \mathrm{m}^{-1} .
\end{gathered}
$$

It should be pointed out that the values of the tidal current speed, horizontal salinity gradient, and buoyancy frequency chosen for the model run are fairly typical of the conditions found in partially mixed estuaries.

[19] Stacey et al. [2001] defined a horizontal Richardson number to examine the local balance between the stratifying and destratifying forces at the tidal timescale,

$$
R i_{x}=-\frac{g \beta H^{2} \partial \bar{S} / \partial x}{u_{*}^{2}},
$$

where $u *$ is the bottom frictional velocity. They suggested that $R i_{x}$ is a valuable parameter for predicting the onset of residual-creating events. Using the friction velocity calculated from the LES model, we find that the tidally averaged horizontal Richardson number $\overline{R i_{x}}=1.38$, which is larger than those in the weakly stratified conditions studied in Li et al. [2008].

[20] One limitation of the model setup is that there was no feedback between the salinity gradient and the net salt flux, as there would be in a real estuary. The particular selection of salinity gradient and tidal velocity for this simulation produced an excess in advective buoyancy flux, leading to a temporal increase in stratification through the simulation, as indicated in Figure 1d. The conditions depicted in this simulation are similar to the conditions in an estuary approaching neap tides, when the stratification often increases at a rate similar to that shown in Figure 1. This run thus represents a case of relatively strong baroclinic pressure gradient, which may favor baroclinically induced processes as compared to tidal straining.

\section{Results}

[21] We have conducted the LES for the parameter set chosen to be representative of a partially mixed estuary with relatively strong vertical stratification. This model run is called Control Run $\mathrm{C}$ to differentiate it from the two other runs with reduced physics (to be discussed in section 4.3). Because of small turbulence scale in the stratified flow, the simulations reported here are much more time-consuming than those LES runs for the periodically stratified case studied in Li et al. [2008]. The calculation of one tidal cycle, in fact, required integration of the governing equations for approximately 1.1 million time steps and 10 days on a 32-processor AMD Opteron cluster.

[22] It should be noted here that, although the depthintegrated velocity (positive values corresponding to flood tides) and bottom friction velocity exhibited the expected periodic behavior, the mean stratification was evolving slowly from one tidal cycle to the other, as noted above. By comparing velocity and salinity statistics taken at correspond- ing points in successive cycles, however, we concluded that this variation did not significantly affect the turbulence statistics. Hence we will present statistical data that are averaged over a plane parallel to the bottom boundary rather than phase-averaged over several cycles. Note that this is consistent with experimental measurements, in which short-time averages are often used instead of phase averages.

\subsection{Reynolds-Averaged Velocity and Salinity}

[23] First we examine vertical profiles of horizontally averaged velocity and salinity at several times during a tidal cycle. The vertical profile of the mean velocity shows large differences between the flood and ebb tides: the velocity has a subsurface maximum on flood but increases monotonically with height on ebb (Figure 2a). This asymmetry in the mean velocity profile appears to be caused by the horizontal pressure gradient associated with sloping isopycnals and surface [e.g., Geyer et al., 2000]. Stacey et al. [2001] suggested that tidal asymmetry in velocity profiles can be also driven by tidal variations in stratification that cause tidal variations in mixing. We, however, found that the mean-flow asymmetry disappears if the baroclinic pressure gradient is switched off in the momentum equation. As a result of this horizontal pressure gradient, velocity at the two slack tides is not reduced to zero. When averaged over the tidal cycle, the vertical profile of the mean velocity shows a typical two-layer estuarine exchange flow with the surface layer moving seaward (negative) and the bottom layer moving landward (positive). The vertical profiles of the mean salinity show the evolution of the bottom boundary layer over the tidal cycle (Figure 2b). The boundary layer grows during the flood tide, with the boundary layer height increasing between peak flood and the slack after flood (or slack before ebb). In contrast, the boundary layer restratifies during the ebb tide, with stratification almost reaching to the bottom boundary at the end of the ebb tide (or slack before flood). The tidally averaged salinity profile shows a boundary-layer height that is intermediate between the flood and ebb values.

[24] Figure 3 shows the temporal evolution of the mean velocity and salinity over the whole tidal cycle. Again, the velocity profiles reveal the flood-ebb difference. One can trace the temporal evolution of the mean velocity profile by marking the location of subsurface velocity maximum (shown in Figure 3a). Early in the tidal cycle, the velocity maximum is located close to the bottom. With stronger flooding current, the height of the velocity maximum increases until the ebb phase. As the ebbing tide gains strength, the baroclinic pressure gradient works in concert with the tidal force to create a monotonically increasing velocity profile. It is interesting and worth noting that during the late ebb tidal stage the flow is directed landward in the lower half of the water column but seaward in the upper half. The landwarddirected baroclinic pressure gradient in the lower layer cancels out or even reverses the seaward directed tidal force in the late stages of ebbing tide, creating a two-layer exchange at the tidal time scale [cf. Stacey et al., 2001].

[25] Temporal evolution of the mean salinity profile shows a well-mixed bottom boundary layer underneath the stratified upper water column (Figure $3 b$ ). There is a general trend of growing boundary layer on flood and retreating boundary layer on ebb. One also notices the gradual increase of salt concentration over the flood tide and decrease over the ebb 

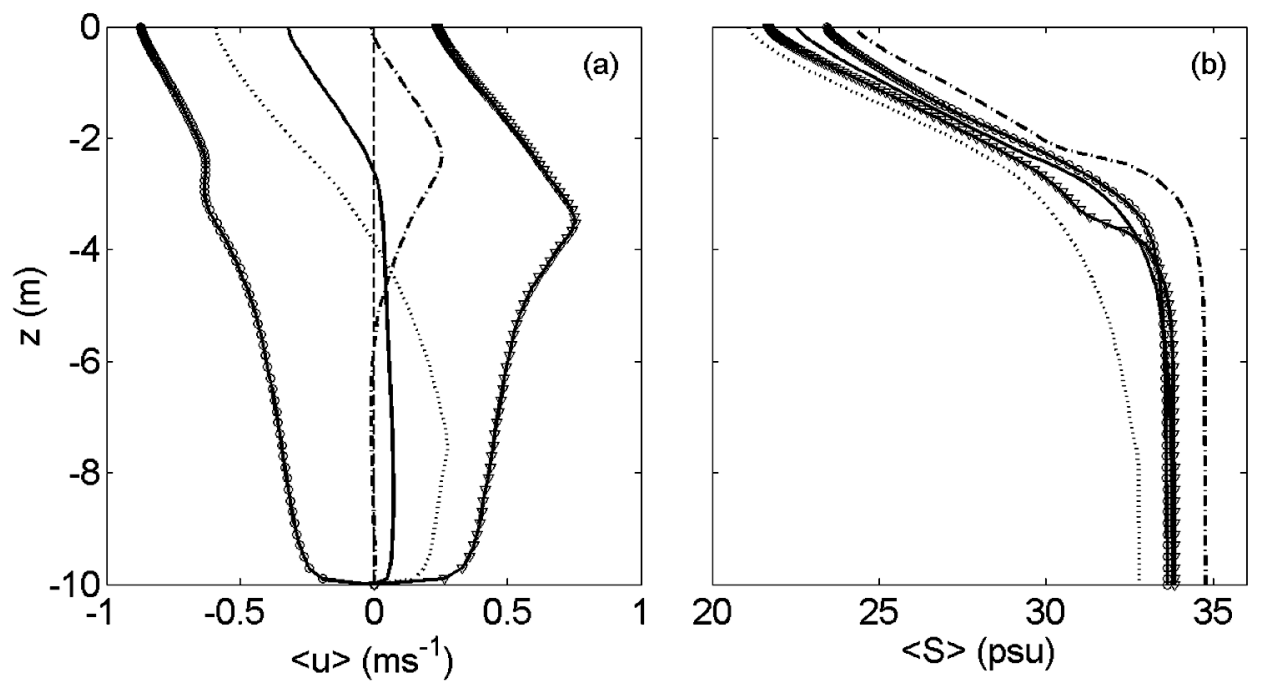

Figure 2. Vertical profiles of horizontally averaged (a) velocity and (b) salinity at slack before flood (dotted), peak flood (solid and triangles), slack before ebb (dash-dot), and peak ebb (solid and open circles). The solid lines represent the mean profiles averaged over the tidal cycle while the dashed line in Figure 2a shows the zero velocity line.

tide, resulting from tidal advection across the horizontal salinity gradient. Although the location of the subsurface velocity maximum has been used to estimate the height of the bottom boundary layer on the flood tide by Chant et al. [2007], it cannot be applied to the ebb phase. Instead we employ a traditional method to define the boundary-layer depth $\delta$ by locating the height at which $\left(S-S_{\text {bottom }}\right) /\left(S_{\text {top }}-S_{\text {bottom }}\right)=\lambda=$ 0.05 . Although the choice of $\lambda$ is somewhat arbitrary, we found $\lambda=0.05$ provides a height of bottom boundary layer in good agreement with the height of the velocity maximum during the flood tide and is consistent with commonly used definitions of the ocean mixed layer depth. Figure $3 b$ shows the growth and entrainment of bottom boundary layer during the flood tide but restratification during the ebb tide. It is worth noting that the density gradient in the pycnocline region becomes sharpened as the bottom boundary layer entrains during the flood, which is suggestive of a boundary layer growth driven by the boundary stress. As the bottom boundary layer retreats, stratification is reestablished throughout the water column consistent with differential advection associated with ebb tidal straining. Finally, we note that the top-bottom salinity difference, or, equivalently, the overall vertical stratification, increases slightly in the beginning of flood tide but then decreases as the flooding tidal current causes mixing and entrainment (Figure 3c). This stratification continues to decrease onto the beginning phase of the ebb tide. As the ebbing current gains in strength, however, the tidal straining causes restratification in the water column and a rebound in the top-bottom stratification.

\subsection{Reynolds-Averaged Second-Order Quantities}

[26] Now we examine the second-order turbulence statistics obtained from the LES model. Figure 4a shows the vertical profiles of the momentum flux at different phases of the tidal cycle. The momentum flux shows a strong flood-ebb asymmetry and is twice as large on flood as on ebb. It decays nearly linearly with the height above the bottom. As the bottom boundary is approached, the resolved momentum flux decreases while the unresolved subgrid-scale flux (which is not included in the plots shown in Figure 4) increases. For comparison, we also plot the tidally averaged momentum flux in Figure 4a. It is much smaller than the peak flood or ebb fluxes and bears no simple relationship with the tidally averaged two-layer exchange flow shown in Figure 2a.

[27] In contrast to the momentum flux, which is primarily driven by the bottom stress, the salt flux drops to zero at the bottom, as shown in Figure 4b. Most of the salt flux occurs between -4 and $-8 \mathrm{~m}$ depths. The salt flux on peak flood is twice as large as that on peak ebb. The salt flux increases from zero at the bottom to a maximum at a height slightly below the top of the boundary layer. It then drops rapidly as the stratified pycnocline is approached. It is interesting to note that the salt fluxes at the two slack tides are much smaller than at peak flood/ebb but are non-negligible. In particular, the salt flux at the slack before flood is nearly as large as the tidally averaged salt flux.

[28] Figure 5a shows the time-depth distribution of the momentum flux over the tidal cycle. As expected, the momentum flux switches sign between the flood and ebb tides and decays with the height above the bed. It is interesting to note that it maintains the same sign at all depths during the flood phase, even though shear in the mean flow on flood switches sign across the subsurface velocity maximum (marked by the thick solid line in Figure 5a). In a small region above the velocity maximum, the velocity shear is negative, whereas the momentum flux is positive. Therefore, the momentum fluxes are countergradient there during the midflood. This is an indication for the nonlocal effects of mixing. The turbulent eddies are likely originated inside the bottom boundary layer and get transported across the velocity maximum. We will return to this topic when examining the turbulent kinetic energy budget in Section 4.1.

[29] Figure 5b shows the vertical distribution of salt flux through the tidal cycle. Most of the salt flux is concentrated in the middle and upper parts of the bottom boundary layer. These salt flux values convert to a buoyancy flux of about 


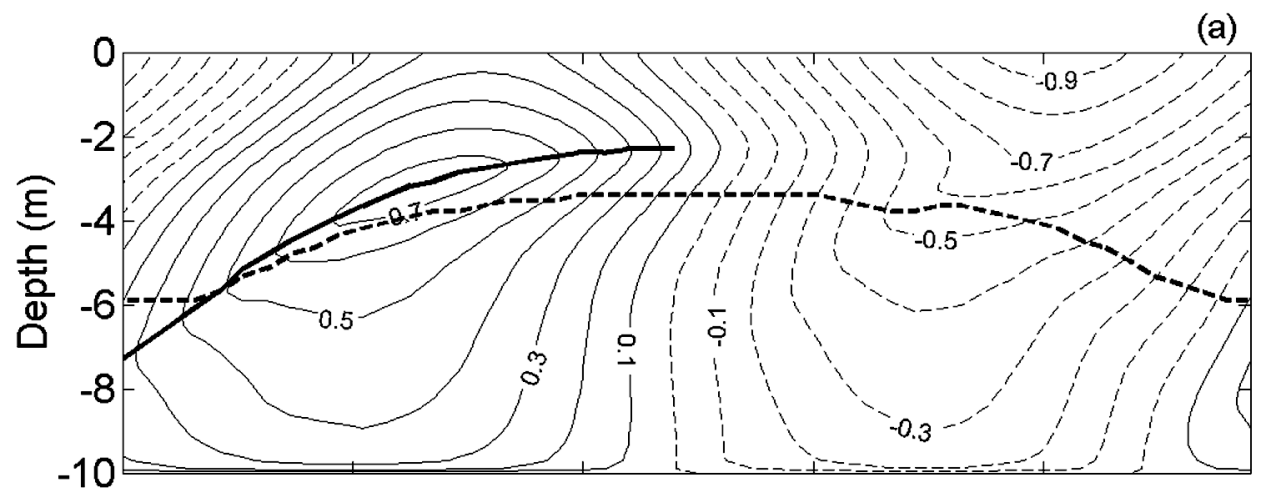

(a)
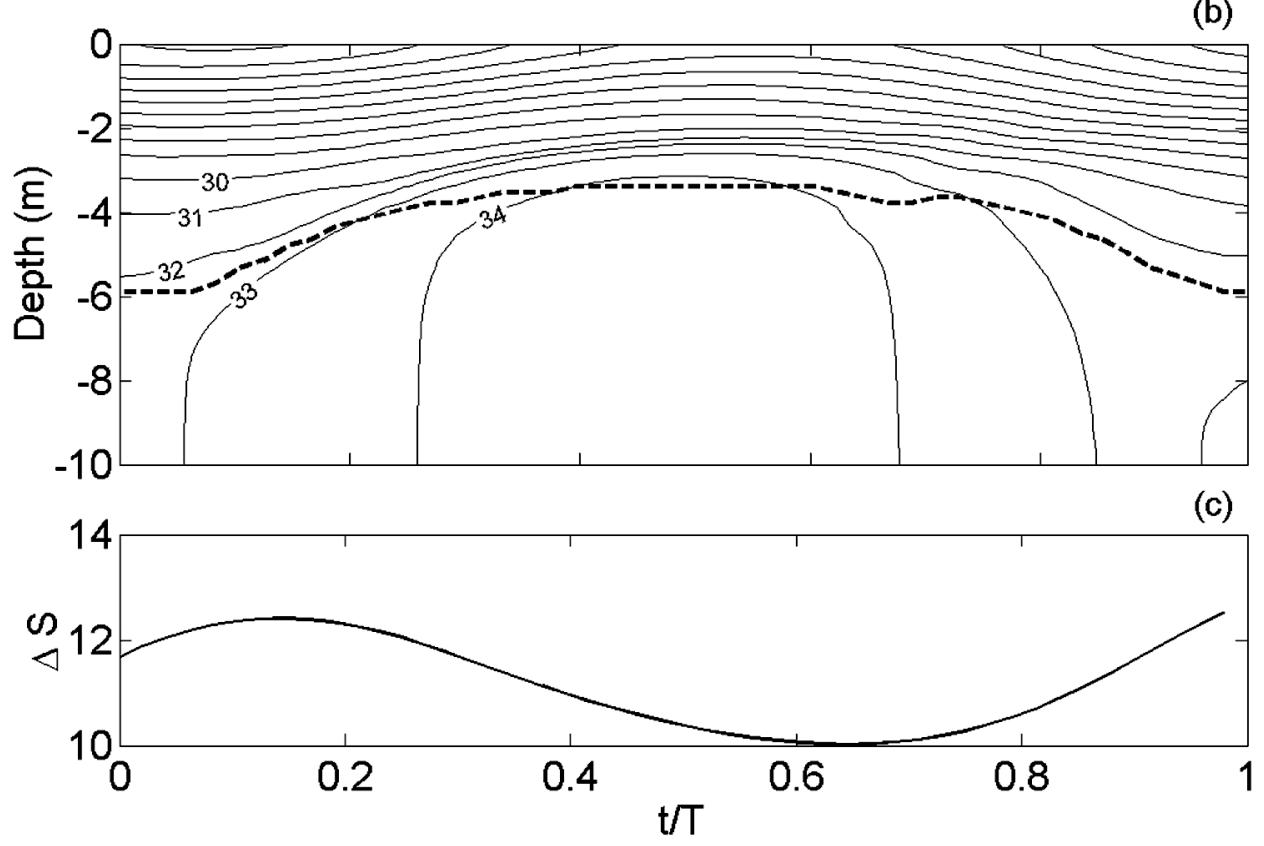

Figure 3. Temporal evolution of Reynolds averaged (a) current, (b) salinity, and (c) top-to-bottom salinity difference over a tidal cycle. Contour levels are in increments of $0.1 \mathrm{~ms}^{-1}$ in Figure $3 \mathrm{a}$ and $1 \mathrm{psu}$ in Figure $3 \mathrm{~b}$. Thick solid line represents the location of subsurface velocity maximum while the thick dashed line is the height of the bottom boundary layer determined from vertical salinity profiles.

1-2 $\times 10^{-6} \mathrm{~m}^{2} \mathrm{~s}^{-3}$, which are in the observational range reported by Peters and Bokhorst [2001] and Chant et al. [2007]. Like the momentum flux, the salt flux also shows a strong flood-ebb asymmetry. Between mid- and late flood, there are weakly unstable density gradients in the lower part of the bottom boundary layer, as shown by a slight countergradient flux there. This model result agrees with the suggestion of Rippeth et al. [2001] that tidal straining may produce instabilities in the water column that release additional energy for convective mixing toward the end of the flood tide.

[30] We estimate the eddy viscosity/diffusivity from the ratio of momentum/salt flux to mean velocity/salinity gradient. The distributions of eddy viscosity and diffusivity are very similar, reaching peak values at $2 \mathrm{~m}$ above the bottom and decaying further upward. The peak viscosity/diffusivity reaches $0.01 \mathrm{~m}^{2} \mathrm{~s}^{-1}$ on flood but $0.003 \mathrm{~m}^{2} \mathrm{~s}^{-1}$ on ebb (Figures 5c and 5d). This flood-ebb asymmetry in eddy viscosity is in agreement with the Hudson River observations by Geyer et al. [2000]. The diffusivity and viscosity hover around $10^{-4} \mathrm{~m}^{2} \mathrm{~s}^{-1}$ at the outer part of the bottom boundary layer.

[31] The TKE $\bar{k}=\left(\overline{u^{\prime 2}+v^{\prime 2}+w^{\prime 2}}\right) / 2$ shows a strong asymmetry between the flood and ebb tides, as shown in Figure $6 \mathrm{a}$. TKE reaches its maximum at the bottom boundary and decays almost linearly away from the bottom. Consistent with the findings for the fluxes, the maximum TKE at the peak flood is twice as large as at the peak ebb. To examine the degree of anisotropy in the turbulence field, we calculated the ratio of $\overline{u^{\prime 2}}, \overline{v^{\prime 2}}$, and $\overline{w^{\prime 2}} / 2$ to $\bar{k}$ and found $\overline{u^{\prime 2}} / 2 \bar{k} \approx 0.5, \overline{v^{\prime 2}} /$ $2 \bar{k} \approx 0.3$, and $w^{\prime 2} / 2 \bar{k} \approx 0.2$ inside the bulk of the well-mixed boundary layer. These ratios agree well with those obtained for the homogeneous boundary layer [Nezu and Nakagawa, 1993]. However, as the stratified pycnocline is approached, $\overline{w^{\prime 2}} / 2 \bar{k}$ reduces to 0.1 or less, as shown in Figure $6 \mathrm{~b}$. Further upward, $\overline{w^{\prime 2}} / 2 \bar{k}$ increases again, possibly due to the presence of internal waves. As a diagnostic of the turbulent flow, we plot the time-depth distribution of gradient Richardson number $R i$ calculated from the mean (horizontally averaged) velocity and density profiles (Figure $6 \mathrm{c}$ ). $R i$ is less than $1 / 4$ 

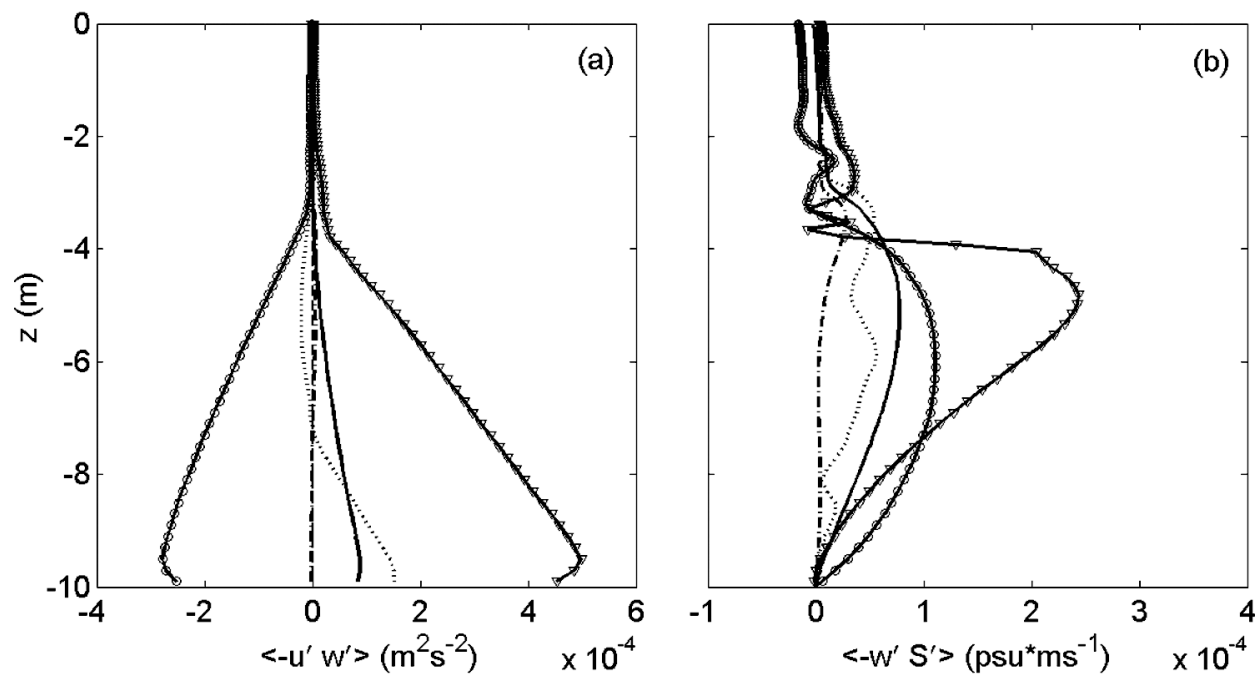

Figure 4. Vertical profiles of horizontally averaged (a) momentum and (b) salt flux at slack before flood (dotted), peak flood (solid and triangles), slack before ebb (dash-dot), and peak ebb (solid and open circles). The solid lines represent the mean profiles averaged over the tidal cycle while the dashed line in Figure $4 \mathrm{a}$ shows the zero stress line.

(a)

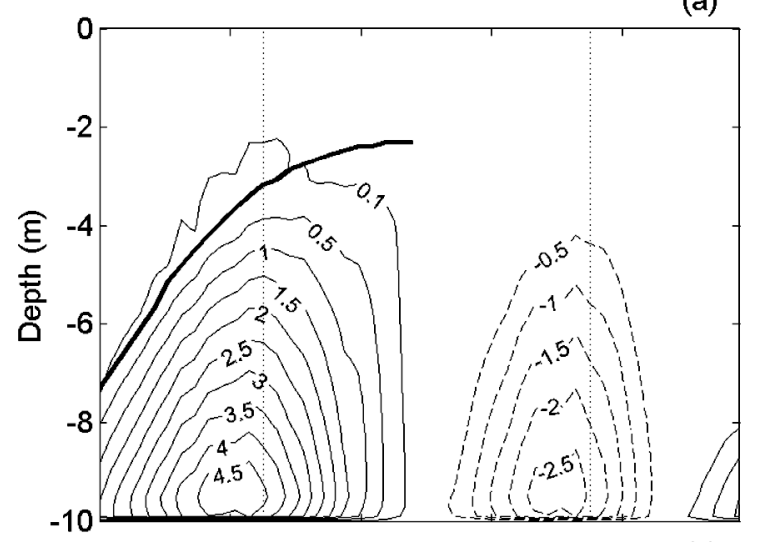

(c)

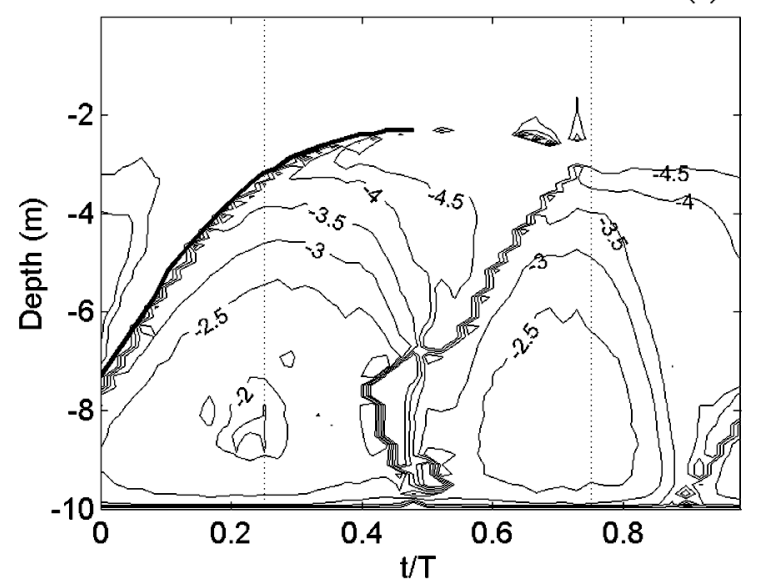

(b)

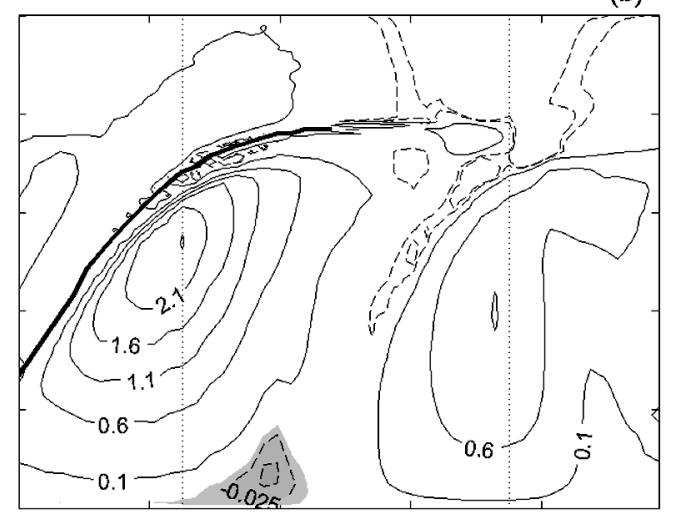

(d)

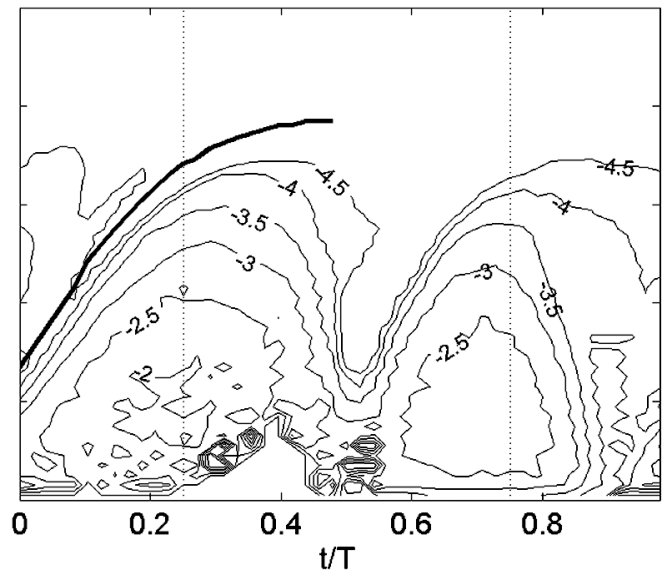

Figure 5. Temporal evolution of horizontally averaged (a) momentum flux, (b) salt flux, (c) logarithm of eddy viscosity, and (d) eddy diffusivity $\left(\mathrm{m}^{2} \mathrm{~s}^{-1}\right)$ over a tidal cycle. The momentum and salt flux are multiplied by $10^{4}$ and are in units of $\mathrm{m}^{2} \mathrm{~s}^{-2}$ and $\mathrm{ms}^{-1} \mathrm{psu}$, respectively. The thick solid line represents the location of the subsurface velocity maximum. The shaded area in Figure $5 \mathrm{~b}$ indicates a region of convective instability. The vertical dashed lines correspond to peak flood and ebb tides. 
(a)

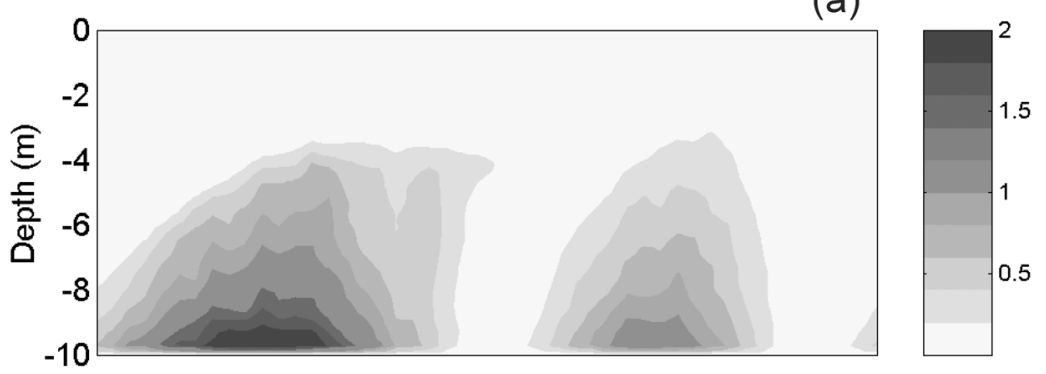

(b)

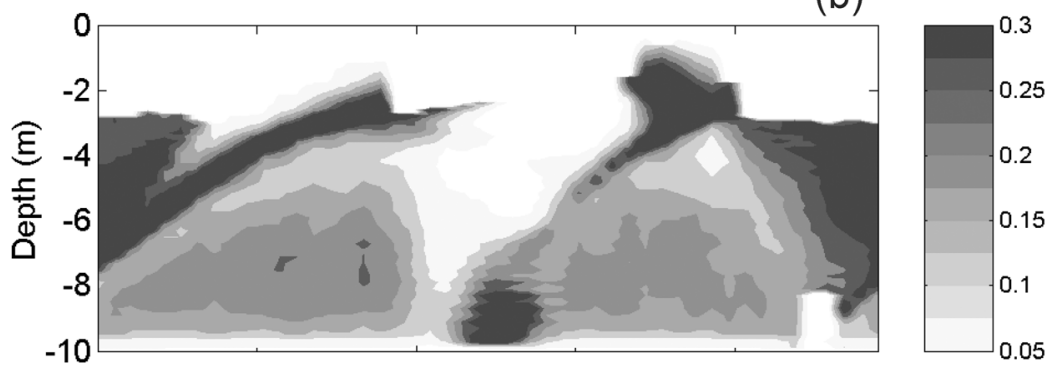

(c)

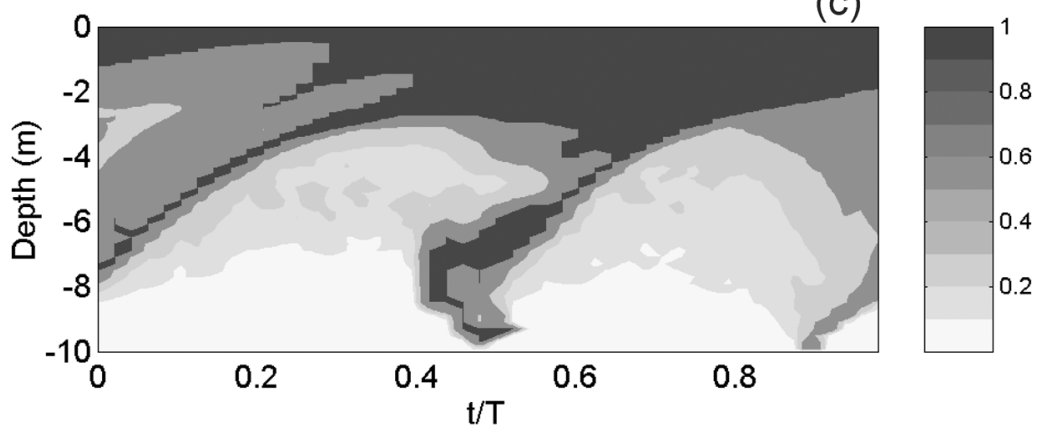

Figure 6. Temporal evolution of (a) TKE multiplied by $10^{3}\left(\mathrm{~m}^{2} \mathrm{~s}^{-2}\right)$, (b) ratio of vertical turbulence intensity to TKE, and (c) gradient Richardson number.

inside the bottom boundary layer but becomes large in the stratified water above. Values of $R i>1$ indicate stable regions where turbulence is suppressed by stratification. We also note that $R i=(1 / 4 \leftrightarrow 1 / 2)$ in the outer part of the boundary layer, indicating marginal shear instability there. There is a strong correspondence between regions with $R i<1 / 4$ and regions with high TKE and turbulent momentum flux, which suggests that turbulent regions in the boundary layer are highly unstable to shear instability and hints that shear production is the dominant source of TKE. Although TKE and turbulent momentum fluxes reveal strong flood-ebb asymmetry, the regions where $R i<1 / 4$ do not appear to differ between the flood and ebb tides. A closer examination, however, reveals smaller $R i$ values on flood than on ebb inside the boundary layer.

\section{Discussion}

[32] In the last section, we provided descriptions of the LES results, including the temporal evolution of the mean flow and turbulence statistics over a flood-ebb tidal cycle. Now we use the LES results to address some open questions on estuarine mixing. We will analyze TKE budget to compare the relative magnitudes of shear production versus buoyancy production and conduct two additional runs with reduced physics to examine the relative roles of baroclinic pressure gradient versus tidal straining in generating the flood-ebb mixing asymmetry.

\subsection{TKE Budget}

[33] Measurements near the sea floor indicate an approximate balance between shear production and dissipation [Trowbridge et al., 1999; Shaw and Trowbridge, 2001] in the budget for turbulent kinetic energy. However, measurements by Simpson et al. [1996] and Stacey et al. [1999] suggest that the vertical transport of turbulent kinetic energy might be important away from the bottom boundary. Hence, turbulent energy generated in the bottom boundary layer may be transported to the overlying stratified region. For the estuarine boundary layer affected by tidal straining, we need to establish the relative role of local shear production versus transport in the pycnocline region. In a tidal channel in San Francisco Bay, Stacey and Ralston [2005] found unstable density profiles on flood and suggested that the tidal straining results in a destabilizing buoyancy flux during the flood but a stabilizing buoyancy flux during the ebb. In contrast, the dye-release experiments of Chant et al. [2007] suggested that tidal straining only has a minor effect on the growth of the bottom 

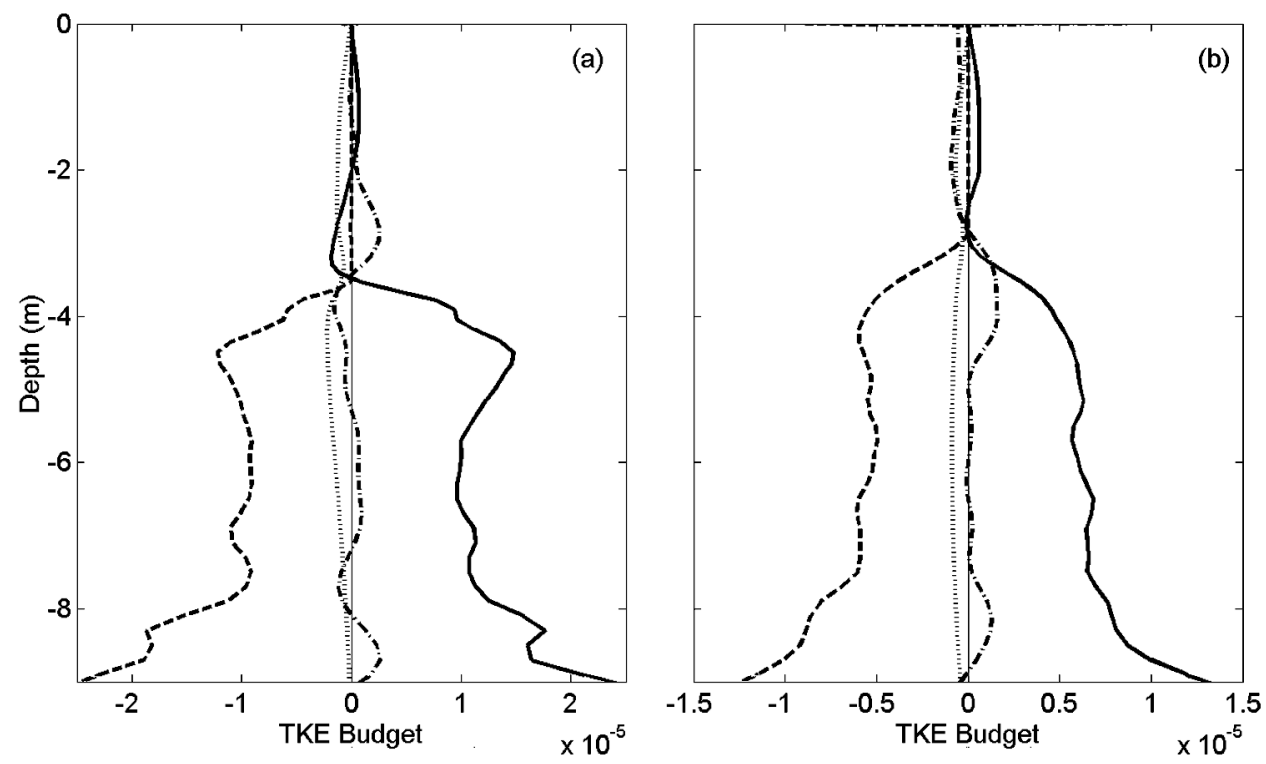

Figure 7. Comparison of TKE budget terms between (a) peak flood and (b) peak ebb tides: (solid) shear production; (dashed) dissipation; (dotted) buoyancy production; (dash-dot) turbulent and pressure transport.

boundary layer on flood. To resolve these apparently contradictory results, we use the LES outputs to examine the horizontally averaged TKE equation,

$$
\begin{gathered}
\frac{\partial \bar{k}}{\partial t}=-\overline{u^{\prime} w^{\prime}} \frac{\partial \bar{U}}{\partial z}-\beta g \overline{w^{\prime} S^{\prime}}-\frac{1}{\rho} \frac{\overline{\partial w^{\prime} p^{\prime}}}{\partial z}-\frac{\partial}{\partial \mathbf{x}} \overline{\left(\frac{1}{2} q^{\prime 2} \mathbf{v}^{\prime}\right)}-\varepsilon \\
\mathrm{S} \\
\mathrm{B}
\end{gathered}
$$

in which terms on the right hand of equation (19) are referred to, respectively, as shear production $(\mathrm{S})$, buoyancy production (B), pressure transport $(\mathrm{P})$, turbulent transport $(\mathrm{T})$, and dissipation (D). Note that the dissipation includes both viscous and SGS contribution, although the latter dominates. In the following analysis, we lump the pressure transport $(\mathrm{P})$ and turbulent transport $(\mathrm{T})$ into one term $(\mathrm{PT})$, representing the net transport or diffusion of TKE as opposed to the local production. The dissipation term $\mathrm{D}$ which involves the calculation of products of velocity gradients is particularly affected by numerical errors at small scales. To avoid these errors, we calculate the time rate of change of $\bar{k}$, and estimate $\mathrm{D}$ using equation (19).

[34] First, we examine the TKE budget at two time instants: peak flood and peak ebb (Figure 7). At first glance, there is a primary balance between the shear production and dissipation in the lower half of the water column (from bed to middepth). The turbulent transport term makes a small but nonnegligible positive contribution to the TKE near the bed but is negligible in the boundary layer, as expected in a shear-driven planetary boundary layer [Moeng and Sullivan, 1994]. Buoyancy production is small and negative, indicating energy consumption through an increase in the potential energy of the water column by mixing. This result is consistent with the measurements near the sea floor of Hudson River estuary [Trowbridge et al., 1999] and the continental shelf [Shaw and Trowbridge,
2001]. However, in the outer part of boundary layer and the stratified pycnocline region $(-4.5$ to $-2 \mathrm{~m})$, other terms become as large as or larger than the shear production and dissipation terms. It is particularly interesting to examine the case at the peak flood, where dissipation and buoyancy production drop to negligible values. However, the turbulent transport term (PT) switches from negative to positive sign at about $-3.5 \mathrm{~m}$ depth, indicating that TKE is being transported across the edge of the boundary layer, from the bottom boundary layer to the stratified pycnocline region. This finding on the role of turbulent transport at the outer part of the bottom boundary layer is consistent with that suggested in the observational investigations by Simpson et al. [1996] and Stacey et al. [1999]. It also appears to be in agreement with other LES simulations of stratified turbulence. In Taylor et al. [2005] simulations of stratified shear flows and Otte and Wyngaard's [2001] simulations of atmospheric inversion layer, turbulent and pressure transports were found to be important in supplying energy to the stratified region and countergradient fluxes were found.

[35] Next, we examine the temporal evolution of all TKE terms over the tidal cycle but focus on the upper $6 \mathrm{~m}$ of the water column (Figure 8), to exclude the bottom $4 \mathrm{~m}$ where the shear production is primarily balanced by dissipation. We zoom into the outer part of bottom boundary layer and the stratified pycnocline region to conduct a close examination on the growth and retreat of the bottom boundary layer. To assist in the interpretation of the budget analysis, we mark the location of the subsurface velocity maximum during the flood phase. Because of the magnitude differences, we use one color scale for the shear production and dissipation but another color scale (a factor of 5 smaller) for the transport and buoyancy production terms. Inside the bottom boundary layer (and underneath the height of velocity maximum on flood), there is a primary balance between shear production and dissipation (between -3 and $-6 \mathrm{~m}$ depths). Both shear production and energy dissipation are larger, reach higher into 
(a)

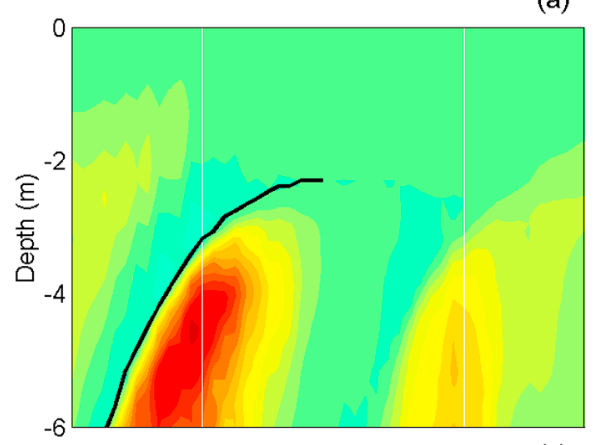

(c)

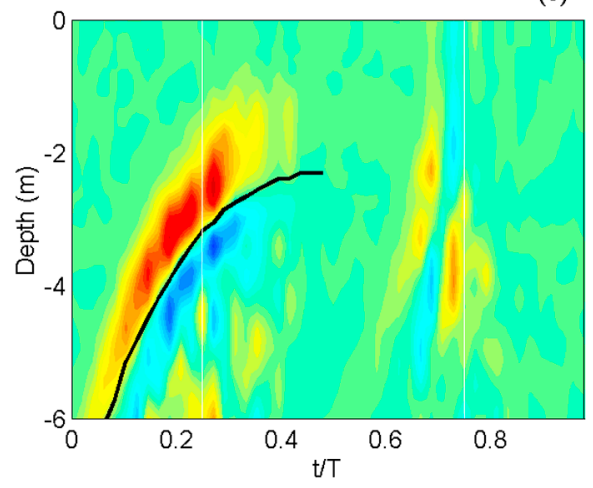

(b)

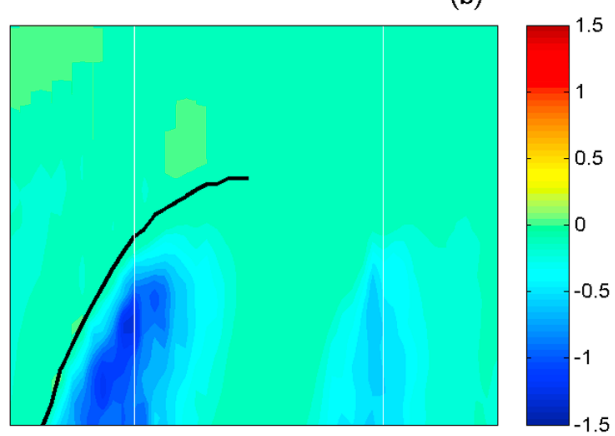

(d)

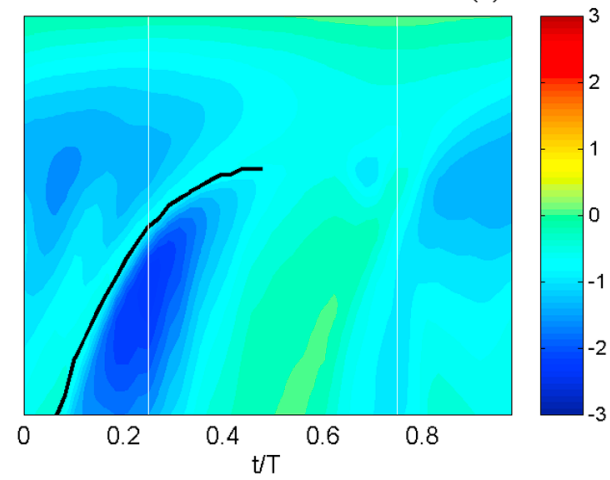

Figure 8. Tidal evolution of (a) shear production, (b) dissipation, (c) pressure and turbulent transport, and (d) buoyancy production. Note that the color scale in the second row is one-fifth of that in the first row. The thick black line marks the location of the subsurface velocity maximum. The two thin white lines correspond to the peak flood and ebb studied in Figure 7.

the water column, and last longer during the flood phase than during the ebb phase. Such a flood-ebb asymmetry reflects the similar asymmetries in TKE and momentum flux noted earlier. It is in agreement with the microstructure measurements of Simpson et al. [2002] who found asymmetric behavior in energy dissipation rates on ebb and flood in a region of freshwater influence in the Irish Sea.

[36] It is particularly illuminating to examine the distribution of shear production and dissipation above the subsurface velocity maximum. Shear production is negligible except in a region immediately above the velocity maximum height where it turns to be negative. As shown in Figures 5a and 3a, the momentum flux during flood shows a monotonic decrease with height while the mean velocity shear switches sign across the subsurface velocity maximum. In the small region above the velocity maximum, the momentum flux (albeit small) appears to have the opposite sign to the gradient of the local mean shear flow, resulting in a negative shear production there. The turbulent eddies can produce a countergradient flux if they are intermittently transported across the level of the velocity maximum. Indeed, we find that the transport is negative below the velocity maximum but becomes positive above it (Figure 8c). The turbulent transport or diffusion transfers turbulent kinetic energy across the subsurface velocity jet. This energy transfer persists from early flood to the peak flood.

[37] Next let us examine the buoyancy production over the tidal cycle (Figure 8d). Based on observations of density and current profiles collected in an estuarine channel in San Francisco Bay, Stacey and Ralston [2005] suggested that the tidal asymmetry may be due to the strain-induced buoyancy flux, which is stabilizing on ebb tides but destabilizing on flood tides. Our results appear to differ from their observational findings. We only found a weak convective region close to the bottom boundary in late flood, as shown in Figures $5 \mathrm{~b}$ and $8 \mathrm{~d}$, but the buoyancy production is much smaller than the shear production. Exclusive of this region, the buoyancy production term remains negative throughout the tidal cycle and the water column, indicating a net conversion of kinetic to potential energy. Hence it seems unlikely that the strain-induced buoyancy flux is the main cause for the flood-ebb mixing asymmetry. In our view, the strong asymmetry in the bottom stress and associated vertical momentum flux between the flood and ebb tides is the primary driver for the flood-ebb mixing asymmetry. In section 4.3, we will conduct two additional runs to further examine the relative roles of the baroclinic pressure gradient and tidal straining.

[38] The ratio of the buoyancy production to the shear production is the flux Richardson number, $R_{f}$, which is a measure of the effectiveness of turbulent mixing in increasing the potential energy of the water column. We have used the LES data to calculate this quantity and investigated how $R_{f}$ varies with $R i$. Figure 9 shows that the flux Richardson number increases with the gradient Richardson number, in agreement with the observations of Peters and Bokhorst [2001]. In the lower half of the bottom boundary layer where $R i<1 / 4, R_{f}$ is significantly less than 0.2 , implying small mixing efficiency in the well-mixed bottom boundary layer. In the upper half of the boundary layer with $1 / 4<R i<1 / 2, R_{f}$ hovers around the value of optimal mixing efficiency (about 


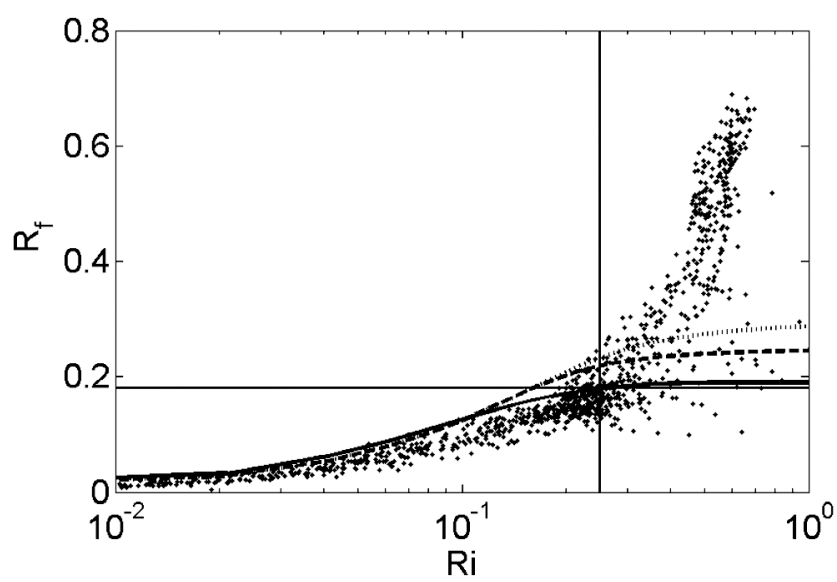

Figure 9. Scatter plot of $R_{\mathrm{f}}$ versus $R i$. Also shown are the analytic and semiempirical formula: solid line for Schumann and Gerz [1995]; dashed for Mellor and Yamada [1982]; dotted for Nakanishi [2001]. Also shown are lines corresponding to $R i=1 / 4$ and $R_{f}=0.18$.

0.2) found in the ocean [Osborn, 1980]. Further up in the water column where $1 / 2<R i<1, R_{f}$ reaches a high value of $0.4-0.7$. Here there are strong vertical gradients in TKE and nonlocal turbulent processes are likely important. This result appears to agree with $R_{f}$ measurements in laboratory experiments of stratified shear flows and stable atmospheric shear flows [Pardyjak et al., 2002]. However, we caution that LES simulations start to lose accuracy in the strong stratified region with high values of $R i$ (see section 4.2 for discussions). For comparison, we also plot the analytic and semiempirical formula obtained by Schumann and Gerz [1995], Mellor and Yamada [1982], and Nakanishi [2001]. These formulae are generally valid only for equilibrium turbulence where there is a balance among energy dissipation, shear, and buoyancy production. Such a TKE balance holds in the energetic bottom boundary layer, as shown in Figures 7 and 8 . It should be noted that most of the LES data points with $R i<1 / 4$ follow the trends in the theoretical curves but fall below them. Recent turbulence measurements in estuaries also found that the mixing efficiency is lower than the theoretical predictions in the energetic estuarine boundary layers (Malcolm Scully, personal communication).

\subsection{Length Scale}

[39] Turbulent length scales in stratified environments range between the small Kolmogorov scale where viscosity takes over and the large Ozmidov scale [Dillon, 1982] where buoyancy suppresses turbulence. We calculate these length scales using the LES outputs and compare them against the model's grid size.

[40] The Ozmidov length scale is defined as $L_{O}=\left(\varepsilon / N^{3}\right)^{1 / 2}$, where $\varepsilon$ is the energy dissipation rate and $N$ is the buoyancy frequency. $L_{O}$ quantifies the maximum size of overturning eddies for a given level of turbulence (characterized by $\varepsilon$ ) and stratification (characterized by $N$ ). The Ellison scale is a quantity to estimate the overturning eddy size using the scalar measurements. It is defined as $L_{E}=\left(\overline{\rho^{\prime 2}}\right)^{1 / 2} \frac{\partial \bar{\rho}}{\partial z}$, in which $\rho^{\prime}$ is the density fluctuation and $\partial \bar{\rho} / \partial z$ is the vertical gradient of mean density [Dillon, 1982]. A third length scale used to characterize turbulent motions is an integral scale that represents the aggregated effect of all the turbulent motions or a master length scale as defined in some turbulence closure models [Mellor and Yamada, 1982]. Using the well-known cascading relation, we can estimate the master length scale of the turbulence flows

$$
L_{U B}=\left(c_{\mu}^{0}\right)^{3} \frac{k^{3 / 2}}{\varepsilon}
$$

where $c_{\mu}^{0}=0.55$ is chosen such that $L_{U B}=\kappa\left(z+z_{0}\right)$ in the logarithmic wall layer [Umlauf and Burchard, 2003].

[41] Figure 10 shows how $L_{O}, L_{E}$, and $L_{U B}$ vary with depth and over a tidal cycle. The Ozmidov and Ellison scales are generally similar in magnitude, with high values (exceeding $1 \mathrm{~m}$ ) in the weakly stratified boundary layer and decreasing to $0.05 \mathrm{~m}$ in the pycnocline. The integral turbulence scale $L_{U B}$ scales with the distance from the bed in the weakly stratified boundary layer, as expected, and it is significantly smaller than $L_{O}$ and $L_{E}$ until the base of the pyconcline. This indicates that stratification does not constrain the turbulence length scale in the part of the flow where the gradient Richardson number is small, consistent with Dillon [1982]. As the stratified pycnocline is approached, $L_{U B}$ decreases and becomes comparable to $L_{O}$ and $L_{E}$. This result also agrees with previous findings that all turbulent scales are of similar magnitude in the stratified pycnocline of the open ocean [Dillon, 1982; Itsweire et al., 1993].

[42] How do these turbulent length scales compare with the model's vertical grid size $\Delta z$ ? We have designed a grid system in which a progressively smaller grid size is used in the outer part of the boundary layer and stratified pycnocline: $\Delta z$ is held at a constant value of $0.2 \mathrm{~m}$ in the bottom $4 \mathrm{~m}(-10$ to $-6 \mathrm{~m}$ ) but decreases linearly further upwards (e.g., $\Delta z=$ $0.17 \mathrm{~m}$ at $-5 \mathrm{~m}$ and $\Delta z=0.07 \mathrm{~m}$ at $-2 \mathrm{~m}$ ). Figure 11 compares the grid size $\Delta z$ with $L_{O}$ and $L_{U B}$ at the peak flood and peak ebb. The grid size is smaller than the turbulent length scales inside the well-mixed bottom boundary layer. As the buoyancy frequency increases and dissipation rate decreases in the stratified pycnocline, however, $L_{\mathrm{O}}$ and $L_{U B}$ decreases with increasing height and falls below $\Delta z$. This is the limitation of the LES modeling approach to simulating high Reynolds number geophysical flows, as noted in Otte and Wyngaard [2001]. It is similar to the one encountered near solid boundaries, where the turbulence mixing length (the distance to the boundary) is equal or smaller than the filter size [Piomelli and Balaras, 2002]. Nevertheless, the LES results are still valuable in elucidating the key physical processes. For example, when simulating the entrainment of the ocean surface mixed layer into the stratified pycnocline, Skyllingstad et al. [1999] noted a similar deficiency in the length scale in the pycnocline but found that the LES model still provides reasonable prediction for key turbulence quantities in good agreement with microstructure measurements.

\subsection{Role of Baroclinic Pressure Gradient Versus Tidal Straining}

[43] Our analysis of the TKE budget shows that the straininduced buoyancy flux is much weaker than the shear production. This suggests that the flood-ebb mixing asymmetry may be primarily caused by the flood-ebb asymmetry in the bed stress rather than the tidal straining of the density field. To 
(a)
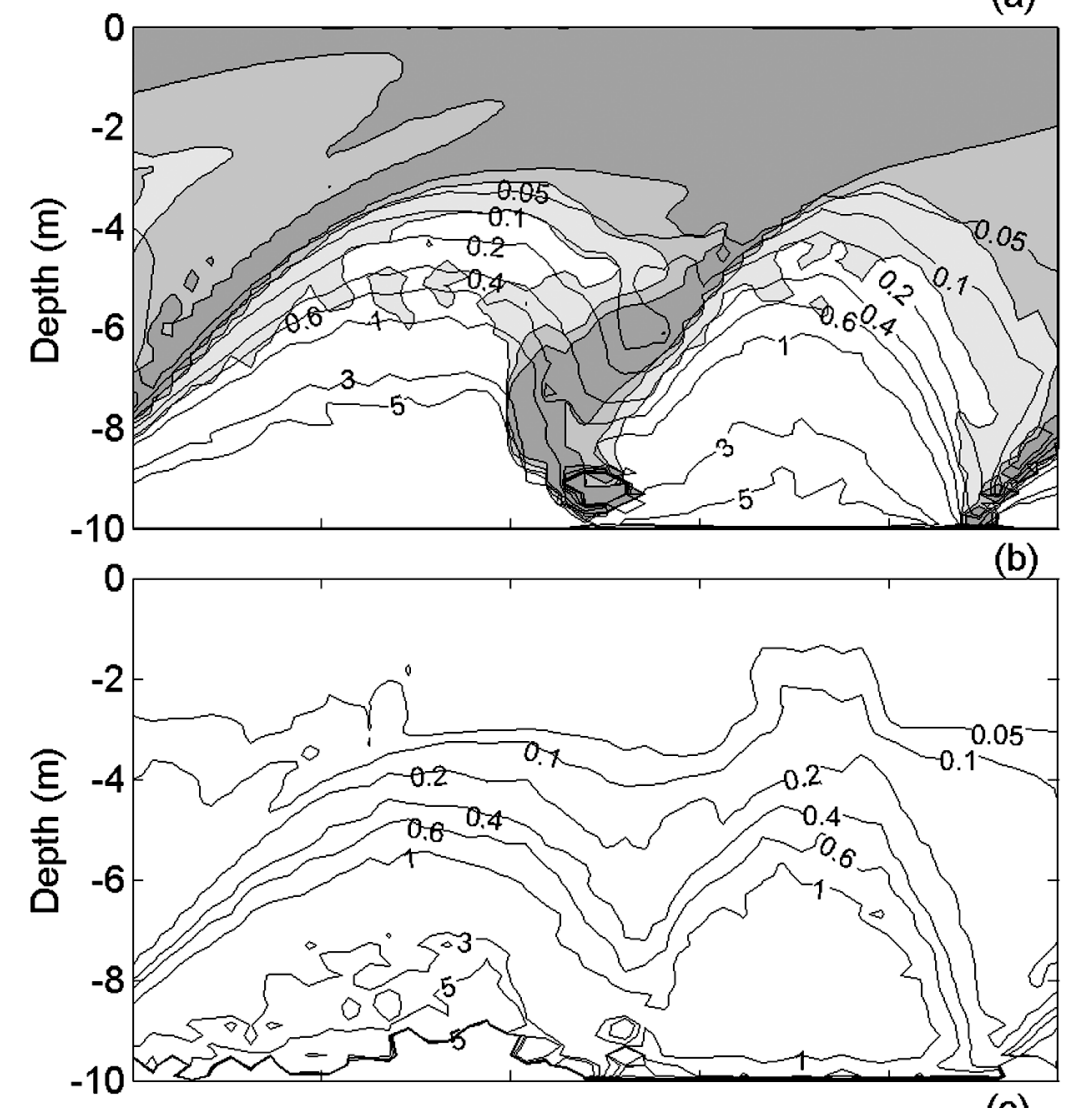

(b)

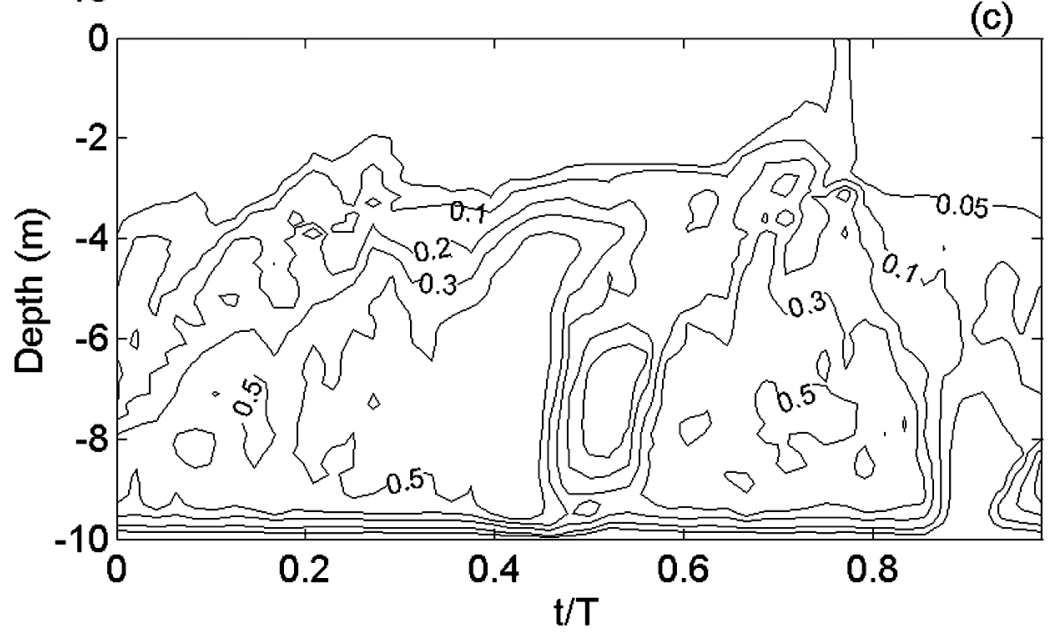

Figure 10. Time-depth distributions of (a) Ozmidov length $L_{O}$, (b) Ellison eddy overturning scale $L_{E}$, and (c) master turbulent length scale $L_{U B}$ over a tidal cycle (in meters). In Figure 10a) the shaded areas indicate $R i<1 / 4$ (white), $1 / 4<R i<1 / 2,1 / 2<R i<1$ and $R i>1$ (darkest gray).

further clarify this issue, we conducted two additional LES runs with reduced physics. In Run A we consider only the effects of tidal straining of density field by switching off the baroclinic pressure gradient (i.e., setting $\partial \overline{P_{b}} / \partial x=0$ ) in the momentum equation (2). In Run B we consider only the effects of baroclinic pressure gradient by switching off the tidal straining term (i.e., setting $u \partial \bar{S} / \partial \bar{x}=0$ ) in the salinity equation (4). These two model experiments were initialized with the velocity and salinity fields from the Control Run $\mathrm{C}$ at the end of tidal cycle 5 and ran for three tidal cycles. We analyze the model results from tidal cycle 3 but recognize that the flow field still evolves with time.

[44] In Run A we find that the stress becomes nearly symmetric between the flood and ebb tides (Figure 12a). This is expected since the baroclinic pressure gradient term that causes the flood-ebb stress asymmetry is switched off. The vertical profile of mean current also appears to be symmetric between the flood and ebb tides. The salt flux pattern is similar to that seen in Control Run C (compare Figures 12b and 5b). It still exhibits a flood-ebb asymmetry but its mag- 


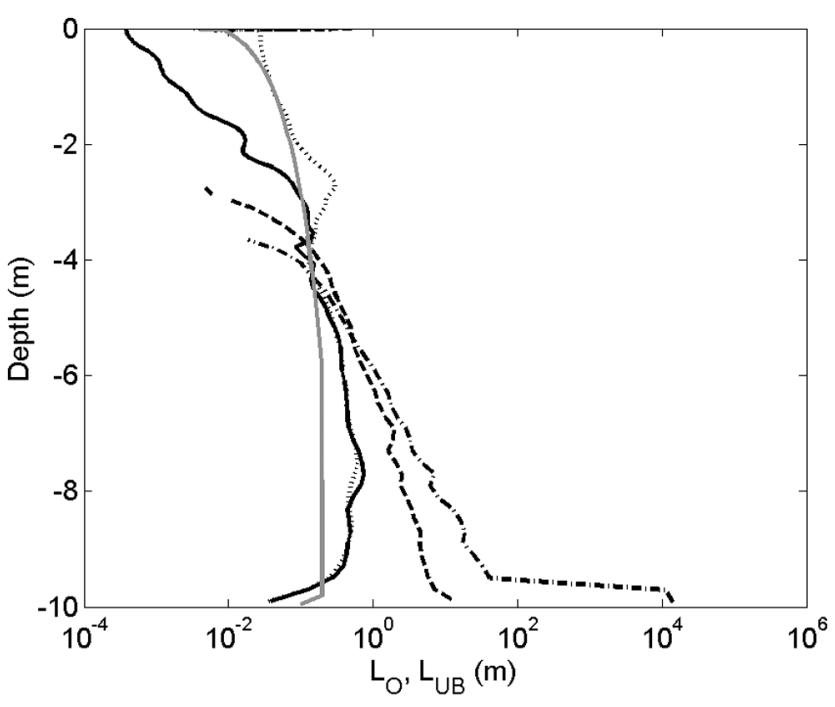

Figure 11. Comparison between Ozmidov length scale $L_{O}$ at peak flood (dash-dot) and ebb (dashed) and master turbulence scale $L_{U B}$ at peak flood (solid) and peak ebb (dotted). The vertical grid size is shown as the gray curve.

(a)

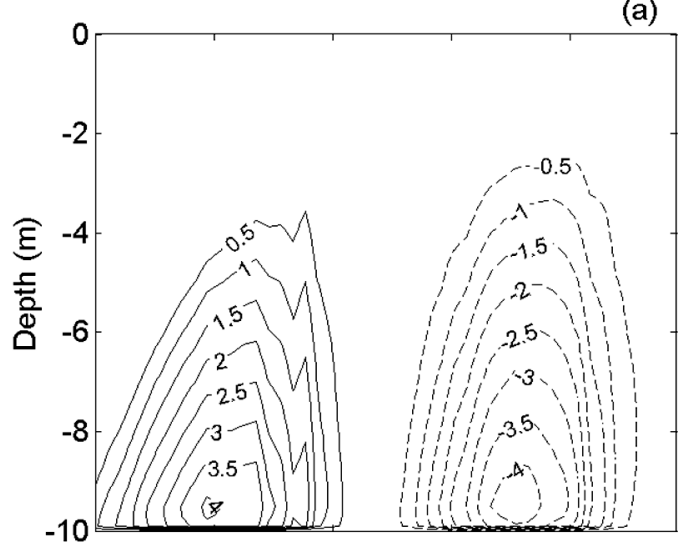

(c)

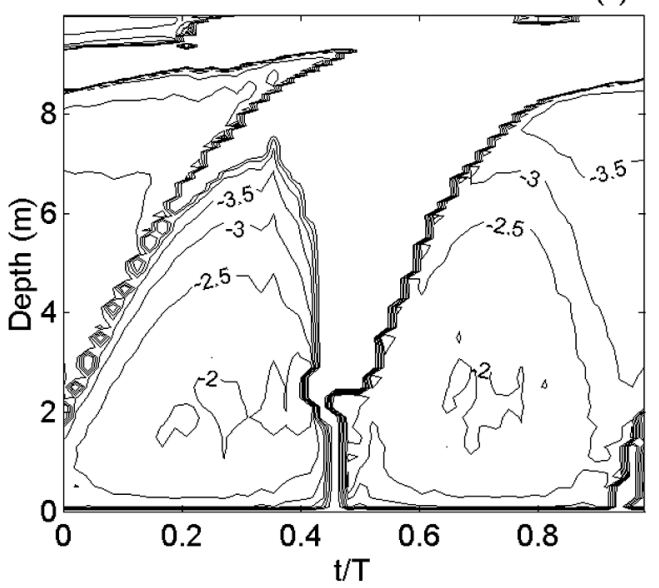

nitude is significantly reduced. Only in a thin layer adjacent to the bottom boundary on the flood tide, one notices slightly convective buoyancy flux. It is particularly interesting to note that both eddy viscosity and TKE are nearly symmetric between the flood and ebb tide (Figures 12c and 12d). The eddy diffusivity has a similar time-depth distribution as the eddy viscosity and does not show a significant flood-ebb asymmetry either. We have examined the TKE budget and found a primary balance between the shear production and dissipation. In summary, we found no evidence that the straining-induced buoyancy flux makes a significant contribution to turbulence generation on flood as suggested in previous studies [e.g., Stacey and Ralston, 2005].

[45] In Run B we only consider the effects of the baroclinic pressure gradient term and switch off the tidal straining $u \partial \bar{S} / \partial x$ in the salinity equation (4). Both the bed stress and mean current show a pronounced asymmetry between the flood and ebb tides, similar to that found in Control Run C. The stratification is much reduced since the tidal straining term that would rebuild stratification during the ebb tide is switched off in the salinity equation. As shown in Figures 13a and 13d, both the momentum flux and TKE shows a strong flood-ebb asymmetry. In comparison, the asymmetry in eddy viscosity is small (Figure 13c). Note

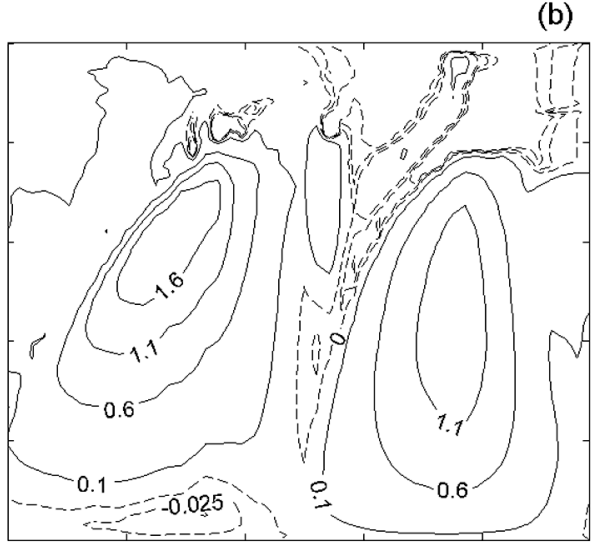

(d)

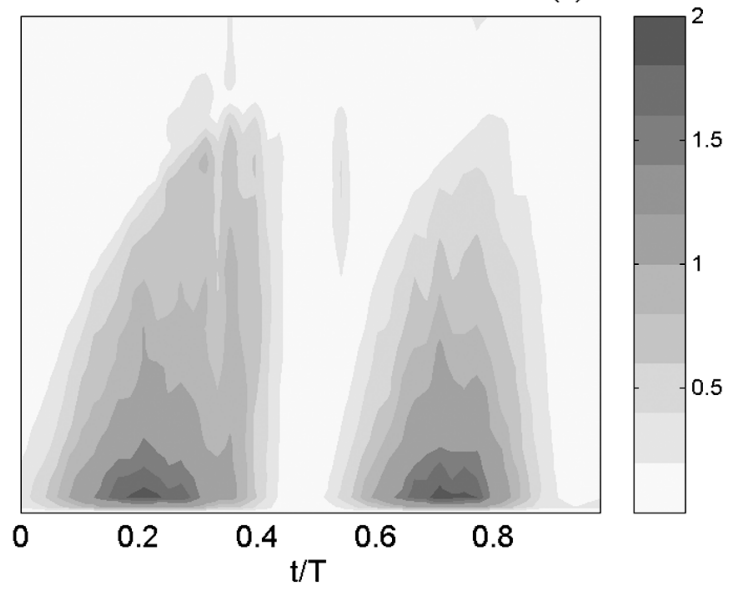

Figure 12. Tidal evolution of (a) momentum flux, (b) salt flux, (c) logarithm of eddy viscosity $\left(\mathrm{m}^{2} \mathrm{~s}^{-1}\right)$, and (d) TKE in the model run in which only the tidal straining term is considered. The momentum and salt flux are multiplied by $10^{4}$ and are in units of $\mathrm{m}^{2} \mathrm{~s}^{-2}$ and $\mathrm{ms}^{-1} \mathrm{psu}$, respectively. TKE is multiplied by $10^{3}$ and in units of $\mathrm{m}^{2} \mathrm{~s}^{-2}$. 
(a)

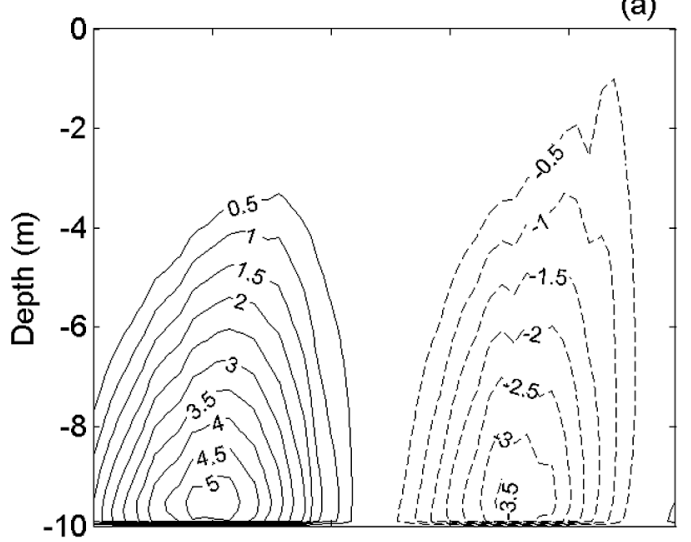

(c)

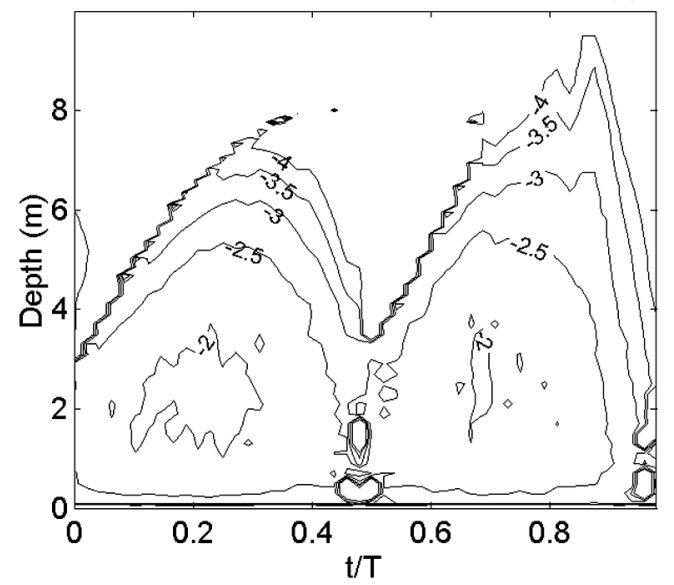

(b)

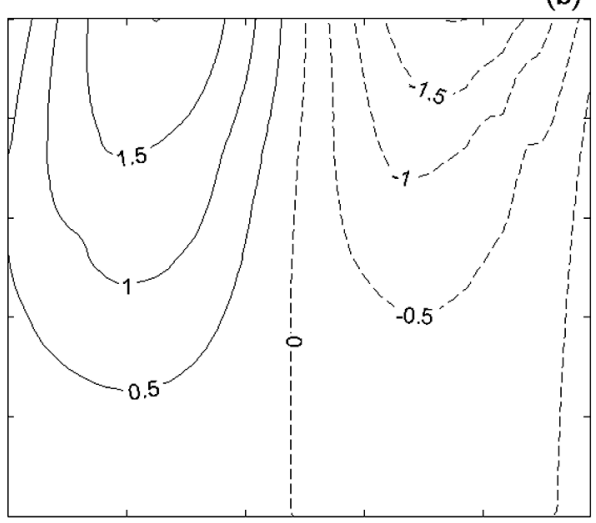

(d)

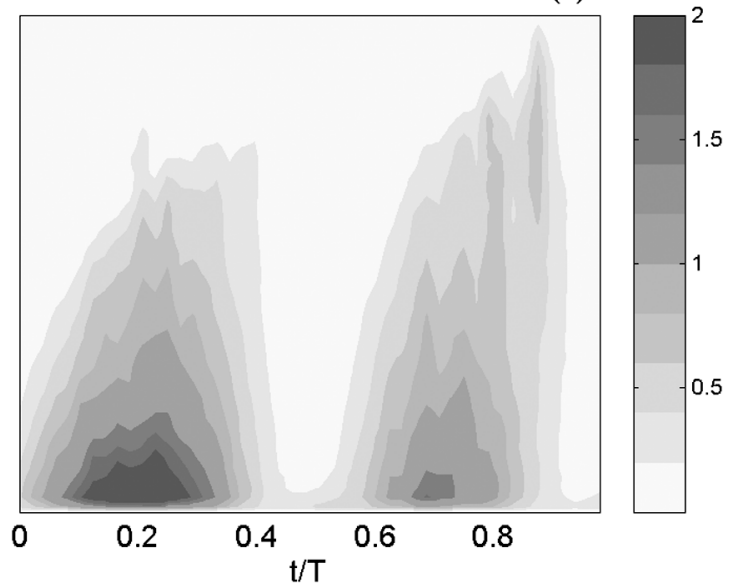

1.5

Figure 13. Tidal evolution of (a) momentum flux, (b) salt flux, (c) logarithm of eddy viscosity $\left(\mathrm{m}^{2} \mathrm{~s}^{-1}\right)$, and (d) TKE in the model run in which only the baroclinic pressure gradient is considered. The momentum flux is multiplied by $10^{4}$ and in units of $\mathrm{m}^{2} \mathrm{~s}^{-2}$ and the salt flux is multiplied by $10^{3}$ and in units of $\mathrm{ms}^{-1} \mathrm{psu}$. TKE is multiplied by $10^{3}$ and in units of $\mathrm{m}^{2} \mathrm{~s}^{-2}$.

that with the decrease in stratification, the high-TKE region on ebb extends all way to the surface. This is accompanied by convective (negative) buoyancy flux. The weakly stratified water is probably conducive to convective instability, but it is not clear how the negative buoyancy flux is produced. An analysis of TKE budget shows that turbulent shear production dominates turbulence-generation on flood but both shear and buoyancy production become important on ebb.

\section{Conclusion}

[46] We have used the LES model to investigate the tidal cycle variations of the estuarine boundary layer and interpret the flood-ebb mixing asymmetry that has been documented in recent observations in estuaries. In agreement with the observations, turbulent kinetic energy, momentum and salt fluxes, bottom stress and energy dissipation rates calculated from the LES model all show a strong flood-ebb asymmetry. We have used the LES results to examine the functional dependence of $R_{f}$ on $R i$ and found that the flux Richardson number increases with the gradient Richardson, in agreement with the previous observations and theoretical modeling.

[47] Analysis of turbulent kinetic energy budget shows a primary balance between shear production and dissipation in the well-mixed boundary layer throughout the tidal cycle. During the flood tide, turbulent and pressure transport terms transfer turbulent kinetic energy across the subsurface velocity maximum, generating a small region of countergradient momentum flux. Therefore, turbulent kinetic energy generated in the bottom boundary layer can be transported to the stratified pycnocline region. After comparing LES Run with full physics and those with reduced physics, we find that the baroclinic pressure gradient is the dominant mechanism for generating the asymmetric turbulent mixing between the flood and ebb tides. Tidal straining of the density field plays only a secondary role. It produces a small and weakly convective region inside the boundary layer during late flood, but the buoyancy production is much smaller than the shear production. However, we must caution that the feedback between the salinity gradient and the net salt flux was not considered in this idealized box model. This may favor baroclinically induced processes as compared to tidal straining. When it is computationally feasible in the future, it would be worthwhile to conduct LES simulations for the entire estuary so that the horizontal salinity gradient can be dynamically determined. At $\overline{R i_{x}}=1.38$ the LES model depicts conditions similar to those in an estuary approaching neap tides when baroclinically induced processes may be more important than tidal straining processes. With increasing computing 
(a)

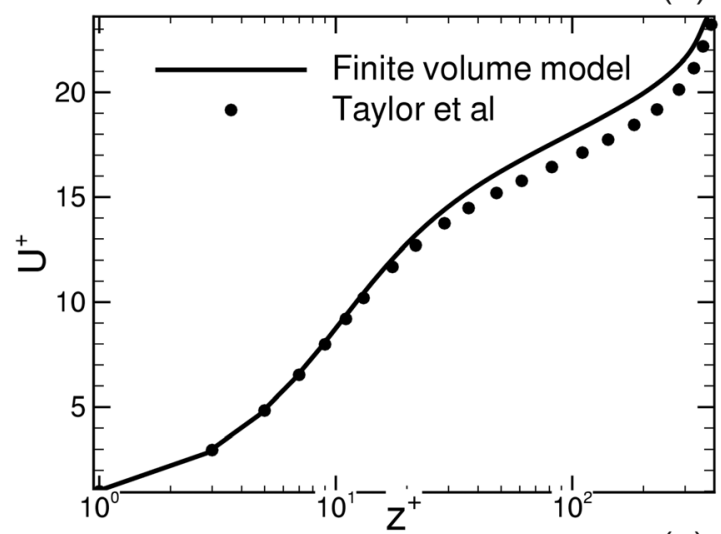

(c)

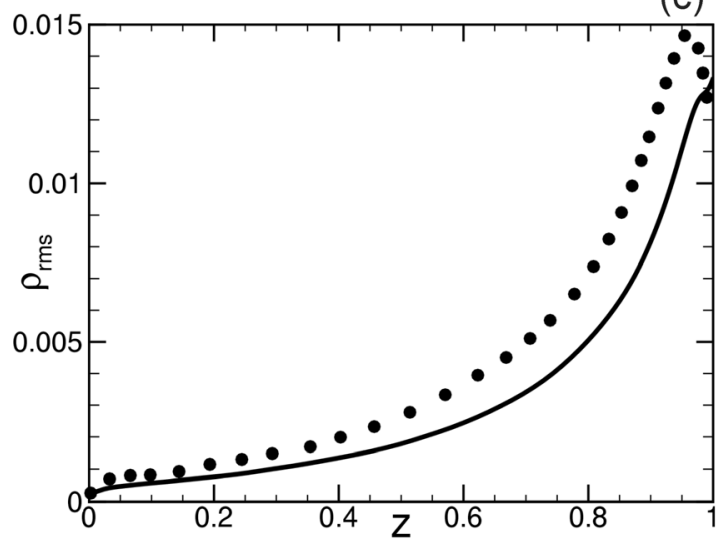

(b)

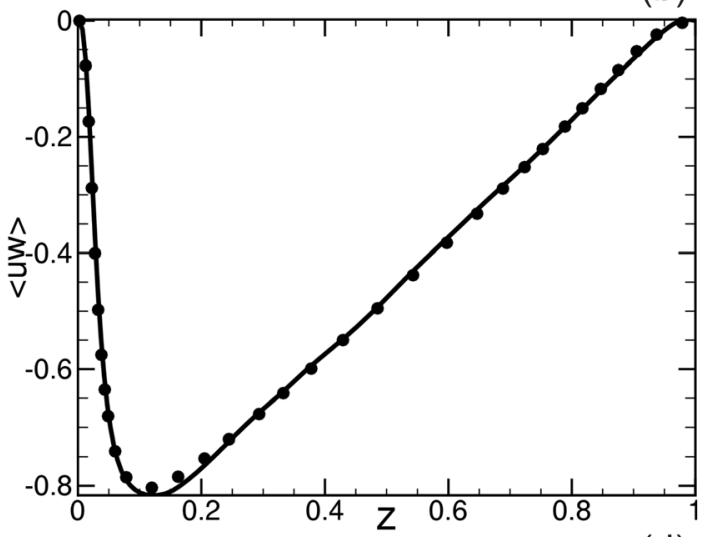

(d)

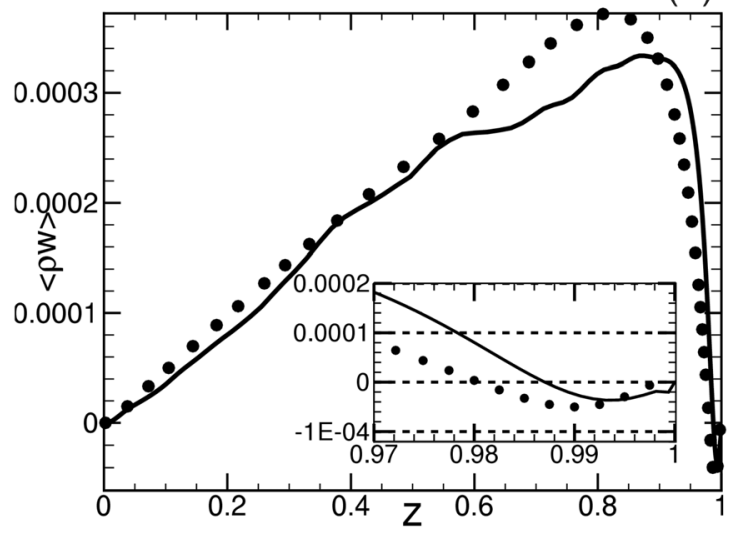

Figure A1. Comparison of (a) mean velocity, (b) momentum flux, (c) density fluctuations, and (d) density flux between Taylor et al. [2005] and the finite-volume code.

resources, we hope to run the LES model over the springneap tidal cycle to examine turbulence dynamics under different stratification conditions.

[48] In addition to the entrainment of bottom boundary layer, vertical salt flux can also occur in an estuary as a result of organized transverse and vertical velocities in estuarine channels or in topographically forced, localized mixing regions such as hydraulic transitions at channel constrictions. The spatial and temporal structure of the vertical transport of salt in estuaries, which must occur to explain the observed salinity distribution, is only beginning to be understood. The finite-volume LES model is well suited to simulate turbulent flows in complex geometry. It is being used to investigate the secondary flow and its interplay with small-scale turbulent eddies. Through these process studies, we hope to gain further insights into the physics of estuarine mixing processes.

\section{Appendix A: Model Validation Against Taylor et al. [2005]}

[49] To examine how well the new finite-volume LES model works in stratified fluids, we compare it with a finitedifference LES model used in Taylor et al. [2005]. This LES model integrates the filtered equations using a fractional step method that is second-order accurate in space and time. The spatial derivatives are computed with central finite differ- ence. The advective terms are time-stepped with the AdamsBashforth scheme while the diffusive terms are advanced with the implicit Crank-Nicolson scheme. The multigrid method is used to solve the Poisson equation for the pressure. This LES model has been extensively validated in previous studies [e.g., Armenio and Piomelli, 2000; Armenio and Sarkar, 2002]. Taylor et al. [2005] used it to simulate stably stratified open channel flow driven by a uniform pressure gradient and a surface heat/density flux. Periodicity is applied in both horizontal directions while flat no-slip and no-stress surfaces bound the bottom and top, respectively. A no-flux boundary is imposed for density at the bottom boundary. Both the model by Taylor et al. [2005] and ours computed a domain of dimensions $2 \pi h \times \pi h \times h$ (in the streamwise, spanwise and normal directions, respectively), using $64 \times$ $64 \times 128$ grid points. Details about the model setup can be found in Taylor et al. [2005]. Here we focus on the comparison between our finite-volume model and their finitedifference model.

[50] The controlling nondimensional parameter for the Taylor et al. [2005] test problem is a Richardson number based on surface forcing conditions defined as

$$
R i_{\tau}=-\frac{g}{\rho_{0}} \frac{\partial \rho^{*}}{\partial z} \mid \frac{H^{2}}{u_{*}^{2}},
$$


where $\rho_{0}$ is the reference density, $\left.\frac{\partial \rho^{*}}{\partial z}\right|_{s}$ is the imposed surface density gradient (for a given density flux), and $H$ is the water depth. In the model comparison run, we choose $R i_{\tau}=500$. Figure A1 shows a comparison of low-order statistics between the two LES models.

[52] In Figure A1a, the mean flow normalized by $u_{*}$ is plotted in the inner wall unit. It fits a logarithmic profile in the lower part of the channel but deviates from it in the upper part due to the effects of stratification. There is good agreement on the mean velocity profile between the two LES models. As shown in Figure A1b, the two models reach nearly perfect agreement on the Reynolds stress profile: a rapid increase to a maximum inside a thin layer and a linear decrease with height as the surface boundary is approached. Figures A1c and A1d show the comparisons of density variances $\rho_{\mathrm{rms}}=\langle(\rho-$ $\left.\langle\rho\rangle)^{2}\right\rangle^{1 / 2}$ and density flux $\left\langle\rho^{\prime} w^{\prime}\right\rangle$ (a prime indicates a fluctuating quantity: $\left.f^{\prime}=f-\langle f\rangle\right)$ between the two LES models. The agreements on the density statistics are not as good as those on the velocity fields but the discrepancies fall within $15 \%$, and may be due to the more advanced SGS model used by Taylor et al. [2005]. The best way to validate a LES model would be to compare the LES results with accurate turbulence measurements in a lab, but we found no appropriate lab data for conducting such a comparison. Given the small discrepancy between the finite-volume LES model and the validated finite-difference LES model, however, we are confident that the new LES model can provide reliable simulations of stratified turbulence in estuarine and coastal flows.

[53] Acknowledgments. This work is supported by grants OCE0451699 (M.L.), OCE-0452380 (U.P. and S.R.), and OCE-0451740 (W.R.G.) from the National Science Foundation. We also acknowledge the computational support from CASPUR (Rome, Italy), where some of the calculations were performed. We thank three reviewers for their helpful comments. This is UMCES contribution number 4399.

\section{References}

Armenio, V., and U. Piomelli (2000), A Lagrangian mixed subgrid-scale model in generalized coordinates, Flow Turbul. Combust., 65, 51-81.

Armenio, V., and S. Sarkar (2002), An investigation of stably-stratified turbulent channel flow, J. Fluid Mech., 459, 1-42.

Brown, A. R., S. H. Derbyshire and P. J. Mason (1994), Large-eddy simulation of stable atmospheric boundary layers with a revised stochastic subgrid model, Q. J. R. Meteorol. Soc., 120, 1485-1512.

Chant, R. J., W. R. Geyer, R. Houghton, E. Hunter, and J. Lerczak (2007), Estuarine boundary layer mixing processes: insights from dye experiments, J. Phys. Oceanogr., 37, 1859-1877.

Denaro, F. M., G. De Stefano, D. Iudicone, and V. Botte (2007), A finite volume dynamic large-eddy simulation method for buoyancy driven turbulent geophysical flows, Ocean Modell., 17, 199-218.

Dillon, T. M. (1982), Vertical overturns: A comparison of Thorpe and Ozmidov length scales, J. Geophys. Res., 87(C12), 9601-9613.

Geyer, W. R., J. H. Trowbridge, and M. M. Bowen (2000), The dynamics of a partially mixed estuary, J. Phys. Oceanogr., 30, 2035-2048.

Itsweire, E. C., J. R. Koseff, D. A. Briggs, and J. H. Ferziger (1993), Turbulence in a stratified shear flows: Implications for interpreting shear-induced mixing in the ocean, J. Phys. Oceanogr., 23, 1508-1522.

Jay, D. A., and J. D. Smith (1990a), Residual circulation in shallow estuaries I. Highly stratified, narrow estuaries, J. Geophys. Res., 95(C1), 711-731. Jay, D. A., and J. D. Smith (1990b), Residual circulation in shallow estuaries II. Weakly stratified and partially mixed, narrow estuaries, J. Geophys. Res., 95(C1), 733-748.

Jensen, B. L., B. M. Sumer, and J. Fredsoe (1989), Turbulent oscillatory boundary layers at high Reynolds numbers, J. Fluid Mech., 206, 265-297.

Leonard, A. (1974), Energy cascade in large-eddy simulations of turbulent fluid flows, Adv. Geophys., 18A, 237-248.
Li, M., C. Garrett, and E. Skyllingstad (2005), A regime diagram for classifying turbulent large eddies in the upper ocean, Deep Sea Res., Part I, $52,259-278$

Li, M., J. Trowbridge, and W. R. Geyer (2008), Asymmetric tidal mixing due to the horizontal density gradient, J. Phys. Oceanogr., 38, 418-434.

Mason, P. J. (1994), Large-eddy simulation: A critical review of the technique, Q. J. R. Meteorol. Soc., 120, 1-26.

Mason, P. J., and S. H. Derbyshire (1990), Large-eddy simulation of the stably-stratified atmospheric boundary layer, Boundary Layer Meteorol., $53,117-162$.

McWilliams, J. C., P. P. Sullivan, and C.-H. Moeng (1997), Langmuir turbulence in the ocean, J. Fluid Mech., 334, 1-30.

Mellor, G. L., and T. Yamada (1982), Development of a turbulence closure model for geophysical fluid problems, Rev. Geophys. Space Phys., 20, 851-875.

Meneveau, C., T. S. Lund, and W. H. Cabot (1996), A Lagrangian dynamic subgrid-scale model of turbulence, J. Fluid Mech., 319, 353-385.

Moeng, C.-H., and P. P. Sullivan (1994), A comparison between shear- and buoyancy-driven planetary boundary layer flows, J. Atmos. Sci., 51, 999-1002

Nakanishi, M. (2001), Improvement of the Mellor-Yamada turbulence closure model based on large-eddy simulation data, Boundary Layer Meteorol., 99, 349-378.

Nezu, I., and H. Nakagawa (1993), Turbulence in Open Channel Flows, A. A. Blkema, Brookfield, VT.

Osborn, T. R. (1980), Estimates of the local-rate of vertical diffusion from dissipation measurements, J. Phys. Oceanogr., 10, 83-89.

Otte, M. J., and J. C. Wyngaard (2001), Stably stratified interfacial-layer turbulence from large-eddy simulation, J. Atmos. Sci., 58, 3424-3442.

Pardyjak, E. R., P. Monti, and H. J. S. Fernando (2002), Flux Richardson number measurements in stable atmospheric shear flows, J. Fluid Mech. 459, 307-316.

Peters, H., and R. Bokhorst (2001), Microstructure observations of turbulent mixing in a partially mixed estuary. II: salt flux and stress, J. Phys. Oceanogr., 31, 1105-1119.

Piomelli, U. (1993), High Reynolds number calculations using the dynamic subgrid-scale stress model, Phys. Fluids A, 5(6), 1484-1490.

Piomelli, U., and E. Balaras (2002), Wall-layer models for large-eddy simulations, Ann. Rev. Fluid Mech., 34, 349-374.

Radhakrishnan, S., and U. Piomelli (2008), Large-eddy simulation of oscillating boundary layers: model comparison and validation, J. Geophys. Res., 113, C02022, doi:10.1029/2007JC004518.

Radhakrishnan, S., U. Piomelli, A. Keating, and A. Silva Lopes (2006), Reynolds-averaged and large-eddy simulations of turbulent nonequilibrium flows, J. Turbul., 7 (63), 1-30.

Rhie, C., and W. Chow (1983), Numerical study of the turbulent flow past an airfoil with trailing edge separation, AIAA J., 21, 1525-1532.

Rippeth, T. P., N. R. Fisher, and J. H. Simpson (2001), The cycle of turbulent dissipation in the presence of tidal straining, J. Phys. Oceanogr., 31, $2458-2471$

Schumann, U., and T. Gerz (1995), Turbulent mixing in stably stratified shear flows, J. Appl. Meteorol., 34, 33-48.

Shaw, W. J., and J. H. Trowbridge (2001), The direct estimation of near-bottom turbulent fluxes in the presence of energetic wave motions, J. Atmos. Oceanic Technol., 18, 1540-1557.

Silva Lopes, A., and J. M. L. M. Palma (2002), Simulations of isotropic turbulence using a non-orthogonal grid system, J. Comput. Phys., 175 (2), 713-738.

Silva Lopes, A., U. Piomelli, and J. M. L. M. Palma (2006), Large-eddy simulation of the flow in an s-duct, J. Turbul., 7 (11), 1-24.

Simpson, J. H., J. Brown, J. Matthews, and G. Allen (1990), Tidal straining, density currents, and stirring the control of estuarine stratification, Estuaries, 13, 125-132.

Simpson, J. H., W. R. Crawford, T. P. Rippeth, A. R. Campbell, and J. V. S. Choak (1996),Vertical Structure of turbulent dissipation in shelf seas, J. Phys. Oceanogr., 26(8), 1580-1590.

Simpson, J. H., H. Burchard, N. R. Fisher, and T. P. Rippeth (2002), The semi-diurnal cycle of dissipation in a ROFI: model-measurement comparisons, Cont. Shelf Res., 22, 1615-1628.

Skyllingstad, E. D., and H. W. Wijesekera (2003), Large-eddy simulation of flow over two-dimensional obstacles: high drag states and mixing, J. Phys. Oceanogr., 34, 94-112.

Skyllingstad, E. D., W. D. Smyth, J. N. Moum, and H. Wijesekera (1999), Upper-ocean turbulence during a westerly wind burst: A comparison of Large-Eddy Simulation results and microstructure measurements, J. Phys. Oceanogr., 29, 5-28.

Smagorinsky, J. (1963), General circulation experiments with the primitive equations. I. the basic experiment, Mon. Weather Rev., 91, 99-164. 
Stacey, M. T., and D. K. Ralston (2005), The scaling and structure of the estuarine bottom boundary layer, J. Phys. Oceanogr., 35, 55-71.

Stacey, M. T., J. R. Burau, and S. G. Monismith (2001), Creation of residual flows in a partially stratified estuary, J. Geophys. Res., 106, 17,013-17,037.

Stacey, M. T., S. G. Monismith, and J. R. Burau (1999), Observations of turbulence in a partially stratified estuary, J. Phys. Oceangr., 29, 1950-1970.

Sullivan, P. P., C.-H. Moeng, B. Stevens, D. H. Lenschow, and S. D. Mayor (1998), Structure of the entrainment zone capping the convective atmospheric boundary layer, J. Atmos. Sci., 55, 3042-3064.

Taylor, J. R., and S. Sarkar (2007), Internal gravity waves generated by a turbulent bottom Ekman layer, J. Fluid Mech., 590, 331-354.

Taylor, J. R., and S. Sarkar (2008a), Direct and large eddy simulations of a bottom Ekman layer under an external stratification, Int. J. Heat Fluid Flow, 29, 721-732.

Taylor, J. R., and S. Sarkar (2008b), Stratification effects in a bottom ekman layer, J. Phys. Ocean., 38, 2535-2555.

Taylor, J. R., S. Sarkar, and V. Armenio (2005), Large eddy simulation of stably stratified open channel flow, Phys. Fluids, 17, 116602, 1-18.
Trowbridge, J. H., W. R. Geyer, M. M. Bowen, and A. J. Williams III (1999), Near-bottom turbulence measurements in a partially mixed estuary: turbulent energy balance, velocity structure, and along-channel momentum balance, J. Phys. Oceanogr., 29, 3056-3072.

Umlauf, L., and H. Burchard (2003), A generic length-scale equation for geophysical turbulence models, J. Mar. Res., 61, 235-265.

Wyngaard, J. C. (1992), Atmospheric turbulence, Annu. Rev. Fluid Mech. $24,205-233$.

M. Li, Horn Point Lab., University of Maryland Center for Environmental Science, 2020 Horn Point Road, Cambridge, MD 21613, USA. (mingli@ umces.edu)

S. Radhakrishnan, Department of Mechanical Engineering, University of Maryland, College Park, MD 20742, USA.

U. Piomelli, Department of Mechanical and Materials Engineering, Queen's University, Kingston, Ontario, K7L3N6 Canada.

W. Rockwell Geyer, Department of Applied Ocean Physics and Engineering, Woods Hole Oceanographic Institution, 93 Water Street MS \#12, Woods Hole, MA 02543, USA 